\title{
Digital storytelling and participatory local heritage through the creation of an online moving image archive: a case-study of Fraserburgh on Film.
}

DAVIDSON, A. and REID, P.H.

This author accepted manuscript is deposited under a Creative Commons Attribution Non-commercial 4.0 International (CC BY-NC) licence. This means that anyone may distribute, adapt, and build upon the work for non-commercial purposes, subject to full attribution. If you wish to use this manuscript for commercial purposes, please contact permissions@emerald.com. 


\title{
Digital storytelling and participatory local heritage through the creation of an online moving image archive: a case-study of Fraserburgh on Film.
}

\section{Andrew Davidson and Peter H Reid}

\begin{abstract}
Design/methodology/approach (limit 100 words)

'Fraserburgh on Film' is an online platform created for the purpose of collating digital heritage film from the communities situated in the corner of North-East Scotland. The research adopted an ethnographic approach working within the community, with James Taylor and other contributors to collect and curate moving images associated with the town. Archival research then supplemented these films. A digital platform was then constructed, tested and launched as the archival repository for the materials collected.
\end{abstract}

\section{Purpose (limit 100 words)}

The aim of the research was to create a site which could host an archive of moving image associated with the town of Fraserburgh in Scotland, but could also include other digital artefacts to support and enhance the narratives contained within the films. Elements of digital storytelling were utilised and a purposely designed section, 'behind the film', was included within the site which saw stories presented and supported with the use of archive newspaper clippings, photography and a series of reflective audio clips recorded for the research.

\section{Findings (limit 100 words)}

The research highlights the importance of having a close association with the community in question, and provides details about the creation of the platform, and framing it in the context of a vehicle for digital storytelling and participatory heritage. The article demonstrates how archive film should be gathered, edited and remaster for long-term preservation and access. Practical aspects such as video hosting, searchability, metadata are explored as are subsequent methods of dissemination and engagement.

\section{Practical implications (limit 100 words)}

The research highlights a number of practical decisions which must be made when considering similar projects. These include gaining access to the moving images in the first place but also significant infrastructural issues around the creation, organisation and dissemination of an online digital repository. These lessons are transferable to other small community-based cultural and heritage organisations.

\section{Social implications (limit 100 words)}

The archive has been very positively received in the community as an important repository for preserving community heritage and identity. High levels of public engagement have been 
demonstrated since its launch which have led to new material being discovered. The archive has a wider cultural legacy across the North-East of Scotland because of both the nature of the films and the widespread use of the Doric dialect.

\section{Originality/value (limit 100 words)}

The originality lies in the distinctive amount of moving image (and oral history) collected by local historian, James Taylor and his willingness to allow his materials to be edited and repurposed to ensure their long-term survival. The lessons learned in this project are transferable to other locations in terms of both collecting material, the creation of the hosting platform, and in crowd-sourcing background information. The crucial importance of working with community partners in digital heritage work is reinforced. The research affords practical illustrations of steps to be taken and factors to be considered. It demonstrates how a wellcrafted digital heritage product can genuinely engage with the community. 


\section{Introduction}

It is said that collective memory can be preserved and solidified in artefacts which represent the cultural heritage of societies and communities (Van Vliet and Hekman 2012). The ease of access to collections of photography, audio recordings and video, afforded by increased digitisation and utilisation of online and digital platforms, has seen an exponential growth in recent years with a focus on representing smaller communities outside the bounds of traditional bearers of archives and collections (Alexander and Hamilton 2016). Artefacts of both tangible and intangible heritage, once held within the constraints of organisational archives and private collections, are being made available for people to reflect, learn and engage with the past, widening access through the process of digitisation and digital dissemination of information (MacDonald, Couldry and Dickens 2015).

Identified by UNESCO as a worldwide concern (Alker and Donaldson 2018) and part of the ongoing strategy of institutions such as the National Library of Scotland (NLS 2015), the creation and preservation of surrogate materials from their conversion to digital formats is seen as a method in which to safeguard artefacts for the future and to widen their accessibility, allowing them to be accessed and viewed by audiences in new ways and for new purposes (Craven 2011). The democratisation of heritage through platforms of digital engagement is an aspiration of many institutions of knowledge (Sabharwal 2015) but, in many instances, the same methods of distribution and consumption are being utilised by smaller groups and even individuals to contribute to, enhance or add new perspectives to the narratives of places and communities and their collective consciousnesses (Cassidy 2012).

Purkis (2017) argues that in creating narratives which reflect the lived histories of communities and individuals, a sense of place and identify can be fostered, encouraging engagement with and participation in cultural heritage. By breathing new life into content a sense of social cohesion can be facilitated (Tait et al. 2013) with collections of digital artefacts have proving popular, as reflected in the success of projects such as Portsoy Past and Present (Beel et al. 2017) and the photo-elicitation research using Buckie Heritage Centre's photography collection (Hood and Reid 2018). These notable projects saw increased engagement with the collections held within archives by making them available to view in the online sphere while simultaneously offering the opportunity to reflect upon the ways in which people consume heritage in this context.

Streaming of digital video has become a dominant method of consuming information online (Ongena et al. 2013). Within the context of heritage, moving image presents the means by which the process of digital storytelling can be supported (Iseke 2011), with digital conversion and 
online hosting slowly unlocking content previously held within the constraints of now obsolete formats and technologies (Taylor and Gibson 2017). Moreover, when considering the conservation of materials for future use, the ability to digitally preserve and present content is also very timely as artefacts stored on analogue formats are at risk of being lost completely, both due to material degradation of the physical storage medium and the obsolescence of hardware on which to view (Iraci 2017).

This research focused on the creation of an online resource entitled 'Fraserburgh on Film'. The site provides a platform for which the collation and presentation of moving images and interviews from Fraserburgh, a town in the North-East of Scotland, and its surrounding villages. Fraserburgh is a town of 13,000 inhabitants at the north-east tip of Aberdeenshire in Scotland, surround by sea on both the north and the east. It is known universally in the local Doric dialect as The Broch. Materials were drawn from a variety of different collections including digitised material held by the Fraserburgh Heritage Centre; however, a significant number of the films were from the vast archive of moving images and interviews created by local historian James Taylor, as well as clips digitised from 8mm film reels donated by local residents. In doing so, the value of these films has been celebrated and a platform created whereby interaction is encouraged, taking inspiration from theories of participatory heritage where a shift in the role of the user is seen from consuming and observing passively to actively participating through contribution and the production of content (Carletti, 2016).

Although some of these films are available to view online through other platforms such as YouTube and Facebook, the creation of the digital archive saw, for the first time, the content being collated together in one place to convey stories from the area through the medium of moving image and other archival materials. The design of a platform for the purposes of digital curation required careful consideration to ensure that it accommodated formats effectively, both those created natively on digital platforms, as well as surrogate materials produced as a result of digitisation from analogue and physical formats (Dallas, 2016). In creating this community archive, the importance of these film artefacts as vehicles for the preservation and celebration of intangible cultural heritage is championed, allowing them to exist within a space which conveys stories and social histories unique to the North-East corner of Scotland.

Having taken these factors into consideration, the aim of the research was, therefore, the creation of an online portal to curate and present heritage film from the Fraserburgh area with a focus on adding value to content through processes of digital storytelling. The aim was underpinned by the following objectives. 
1. Select and collate films from the Fraserburgh area from personal collections created by North-East residents, such as James Taylor, and use these as the basis for research which results in the creation of supplementary materials to further expand upon narratives contained within.

2. Create an online platform to serve as a means to present collated materials where the worth of the content as valuable artefacts of social and cultural history can be promoted.

3. Explore the concept of digital storytelling and use this as a basis for structuring the presentation and manipulation of materials on the platform.

4. Design the platform and the narrative of the project in such a way that interactivity and contribution from the audience is encouraged upon launch through the mechanics of the platform itself and by linking with social media, facilitating the realisation of the project as vehicle for participatory heritage.

\section{Literature review}

This research considered the study of heritage through a number of broad themes. Prominent theories which underpin both the production and opportunities for subsequent study of the platform include: mixed media digital storytelling and the tools in which to conduct this in an online context, digital heritage engagement, using digital platforms to widen access to archive materials and community based participatory heritage.

\section{Digital storytelling}

The origins of the term 'digital storytelling' can be traced back to the 1980s when Atchley first used multimedia items to support storytelling performances (Rossiter and Garcia 2010).

Described as "short vignettes that combine the art of telling stories with multimedia objects" (p. 37), the practice of digital storytelling has most recently found itself a home in the online sphere (Johnson 2018) where digital artefacts are brought together, often on social media networks or online archives, to create "self-representational stories" (Dunford and Jenkins 2017 p.3). Digital storytelling is of particular interest when looking in to the field of digital heritage as the process allows for historical artefacts to be archived and used in such a way that they can convey stories from the past which in turn contribute to the feeling of place and belonging within a community (Alexander and Hamilton 2016).

Hood and Reid (2018) offer insight in to the use of social media as a platform for digital storytelling, concluding that the connectivity permitted make them "successful mechanism[s] for eliciting digital stories" and that "these digital stories are not solely about personal history 
but also local history" (p. 21). Conrad (2013) adds further support to this notion stating that "personal stories can function as a means of building community by connecting community members to one another through a shared archived history" (p. 459). Conrad (2013) also reflects on what Couldry (2008) defines as the "shared infrastructure" which allows communities to create and reflect upon stories which can be assumed to "invigorate the community thereby encouraging participation" (Conrad 2013 p. 462).

Digital storytelling is of particular importance in the context of the practical element of this research. Roued-Cunliffe and Copeland (2017) echo sentiments detailed in other studies stating that the "power of digital connectivity and the ease of creation fuels participation" (p. 2) whereas Erstad and Wertsch (2008) suggest that a dialogue can be created when the community are allowed to become involved in the sharing of one person's experiences. Although the research contained multiple narratives an overarching theme is the story of local historian, James Taylor, and his motivations behind visually documenting social heritage. The research, then, could very much be seen as telling the story of an individual and their own personal past encounters with people who once lived within North-East communities, while inviting current members of the same towns and villages to relive these stories and narratives once again.

\section{Tools for digital storytelling}

Although digital tools can allow people to "tell stories from their own lives...using media to add power and resonance" (McLellan 2006 p. 70), the correct tools must be chosen. It is observed that digital platforms have both the ability to distract and add to the story (Rossiter and Garcia 2010). Parry (2010) states that in the context of museums, digital platforms can often "fetishize the future and neglect the past" (p. 5) while MacDonald, Couldry and Dickens (2015) reflect on the theory developed by Halbwachs (1992), observing that "collective memory requires a material framework or cadre" (p. 103). Although social media platforms offer the ability for users to connect and engage with stories on a personal level (Sinn and Syn 2014) it was decided that for this research it would not act as the sole means by which to host and present material. Economou (2015) argues that "digital technology is not simply an innocent tool in our effort to record and understand the past, for it inevitably affects and shapes drastically how we experience cultural heritage" (p. 225), so a platform which offers the user an experience and that adds value to collated materials was a desirable outcome for the research, adopting a simple and easy to use interface which allowed the content itself to be the main focus and presented without distraction. 
Tait et al. (2013) detail a similar project design where social media was used "to facilitate the transition...to being an online community without compromising the integrity and validity of the core data structure" (p. 31), while Ruge and Denison (2017) observe that social media, when used in conjunction with digital archives, offers the opportunity to promote, engage and expand upon collections but that the curatorial scope of these platforms is limited. The need for careful consideration when designing platforms for digital engagement is echoed by King et al. (2016) who observe that "the medium through which digital engagement occurs can be just as important in defining the cultural value of heritage encounters as the content itself" (p. 88). Moreover, Stuedahl and Mortberg (2012) note that should platforms be chosen which are restrictive and do not allow variety in the presentation of material that a risk exists of imposing a "single unifying ontology" (p. 109) rather than allowing for dynamic presentation.

\section{Digital Heritage Engagement: increasing access}

Heritage receives an almost universal interest (Alexander and Hamilton 2016) and through the work of institutions and conservation projects work is ongoing on local and national levels to help in its preservation (McDonald 2011). Processes of digitisation not only help in the conservation of materials but also permit them being accessed by wider "anonymous and unanticipated audiences" (MacDonald, Couldry and Dickens 2014 p.107). Digitisation turns objects once "held in private shoeboxes or filing cabinets" (p. 114) in to networked, discoverable artefacts which are malleable and inherently able to be repurposed at minimal cost. Mazzanti (2011) observes that technological obsolescence and issues with the degradation of magnetic medium could result in loss of content if materials are not digitised and preserved in this way.

In increasing access to heritage content through combining digitisation of artefacts with online platforms, it could be considered that heritage is being democratised (Henninger and Scifleet 2016; Blackburn 2013). Purkis (2017) suggests that in allowing for a greater number of points of access to heritage content and that basing narratives on "ordinary people's life histories is an important part of the democratisation of heritage" (p. 434). However, despite it arguably leading to the creation of narratives which are "more polyvocal...and less dependent on experts" (Taylor and Gibson 2017 p. 408), thus leading to a greater lever of democratisation of content, there could also be considered a "disconnection between increased access and increased democracy" (p. 409). This sentiment is echoed by King et al. (2016) in stating that emphasis is placed on "breadth of audience and reach, rather than quality of experience" (p. 79). Cameron and Kenderdine (2010) even go as far as to suggest that content is sometimes placed behind 
digital walls or poorly organised in digital archives which can result in access being restricted either deliberately or unintentionally through thoughtless design. However, within the context of this research, these issues were not a concern. Since the aim of the research was to take elements from private collections and use these to tell the story of a community, it could be argued that heritage is in a sense being democratised as the focus is on the stories of everyday lives and not necessarily narratives transcribed by formal memory institutions.

\section{Community engagement}

Democratisation of heritage can also be considered from another angle through the ability of digital heritage to engage members of the community and present a version of history which is dictated by and reflective of personal stories of community members themselves (Duffy and Popple 2017). Tait et al. (2013) state that "digital technologies are facilitating community activity in the collation, production and communication of cultural heritage" (p. 2) while Giaccardi (2012) acknowledges that social media lends users the ability to dictate the nature of heritage stories, highlighting areas of importance and "transforming traditional one way media conversation into an active conversation" (p. 4). This arguably leads to the challenging of perspectives of experts and institutions on what should be considered important elements of cultural history. Mutibwa (2016) suggests that there appears to be a "consensus that memory... tends to be framed by institutions and people in positions of authority" (p. 8), so in presenting content to audiences which may have previously gone unseen or unnoticed, a new perspective on local history and stories can be presented.

One of the primary desires of all heritage projects is to actively encourage engagement with members of the public (Nicholson 2017). Purkis (2017) suggests that in creating narratives which reflect the stories of ordinary people and allowing the presentation of and interaction with information that is "linked intrinsically to people's own lives" (p. 435) that a sense of place can be created and engagement fostered. The idea is further explored by Cassidy (2012) when analysing the Retracing Salford project which used collections of digitised audiovisual materials held in private collections to "rejuvenate a sense of place, despite the eradication of the built and social environment" (p. 166). A number of parallels could be drawn between the communities of Fraserburgh and Salford in this respect as the town centre in Fraserburgh is currently undergoing a process of regeneration following years of neglect, which had led to many feeling it has lost its sense of place.

The power of a heritage project such as this can encourage a sense of ownership in the community of their heritage and physical spaces (Mutibwa 2016). Beel et al. (2017) further 
emphasis this point by suggesting that "community heritage...represents a series of place- based connections between individuals who come together to collect and share their historical narratives" (p. 463) whereas Stevens et al. (2010) suggest that through this initial process heritage work can act as a 'pushing-off' point for further community engagement. Duffy and Popple (2017) add support to this point when looking at heritage in the context of Island Stories, concluding that in creating a "democratised ecosystem" for the project in which "traditionally recognised roles of 'expert' and 'public'"' (p. 3) were reimagined led to the realisation of a project which encouraged community participation and created a sense of place and of a shared heritage.

\section{Audio visual artefacts as tools for heritage engagement}

Following an analysis of a photo-elicitation research Hood and Reid (2018) observed that "photographs play an essential role in the continuity of contemporary culture for the local community" (p. 21), a sentiment which is echoed by Niederee et al. (2018) where the importance of preserving photography is emphasised as it assists in the process of "contextualised remembering" (p. 8) supporting recall in the human brain and active engagement with history. Heritage photography when used in conjunction with social media was seen as powerful way to create a sense of place and unity in the community of Portsoy (Beel et al. 2013) and also when used as part of a multimedia project involving the collection of materials held by Salford Boys Club, where the frameworks utilised allowed the visual collection to act as "contemporary example of collective memory" (MacDonald, Couldry and Dickens 2015 p. 188).

Although several studies examine photography in such a way, few studies focus on the potential of the moving image to serve the same purpose. Ongena et al. (2013) discuss audio visual heritage services but their empirical study mainly focusses on the potential of two online video hosting sites to act as places to engage with video and not necessarily on the ability of video itself to engage audiences. Similarly, when looking at preserving film, Kapse (2015) concentrates on the digitisation of celluloid and how this impacts the perceived worth of the created digital artefact. Other studies also look at digitisation in this respect, questioning whether it diminishes the value of content but this was not a concern for this research. The reverse is actually seen as true as it could be argued that converting the films for use in the project from their original form that further value is being added and, in preserving content, the wealth of information contained within is being acknowledged. 
The theories cited here created a foundation to support the production of the platform but also allowed guidelines to be developed so that the project delivered an online space which would fulfil the desired functions of digital heritage engagement, placing its user base at the centre of considerations.

\section{Methodology}

The research, as well as collection and curation, of film, adopted an ethnographic approach, as the initial data collection involved working within the community, and with James Taylor and other contributors, to gather and select material for use in the portal. Within this framework, the method was "conceptualized as involving participant observation within a community or field of study" (Harrison 2018 p.3). Moreover, Van Maanen (2011) defines an ethnographic study as the "representation of culture as used by particular people, in particular places, at particular times" (p. 155) which further supports the justification of the use of this research design for the project. When researching heritage material to support video artefacts within the portal, adopting this mixed method design allowed for the gathering of information using a number of sources and methods (including conducting interviews with James Taylor himself as well as other members of the community). Considering that the fundamental aspects of an ethnographic study are "participant-observation, writing fieldnotes, and conducting interviews" (Harrison 2018 p 19), the techniques used within this aspect of the research echo that of a traditional ethnographic study.

\section{Collection of data}

Materials, of various formats, were gathered for use within the research and, although moving image serves as the basis of the narrative, still images, sound recordings and newspaper articles were also collected to enhance and contextualise the narratives contained within the film clips.

\section{Film from the James Taylor collection}

James Taylor, a resident of the village of Rosehearty near Fraserburgh, provided a vast quantity of film material and information for use within the research. Over the years, he personally has built an archive of audio-visual recordings, photographs and documents relating to Scottish social culture and traditions, with a focus on the North-East of Scotland. He has written a number of short books and has amassed vast quantities of heritage materials including over 300 hours of audio recordings dating from the 1960s and almost the equivalent volume of film recordings dating from the early 1980s. Having always had an interest in stories and North-East 
culture, James Taylor created this archive with altruistic motives with the sole purpose being the preservation and dissemination of the culture of North-East Scotland. James Taylor was an ethnographic researcher without necessarily realising it, being part of the community and with the keenest of interests in recording and documenting it. Our own project's ethnographical element was facilitated by Andrew Davidson being 'a Broch Loon' [dialect for a Fraserburgh Boy, or a native]. His closeness to the town, his name being recognisable, his family connections known all facilitated access to material in a way that an outsider might have found more problematic.

Although he has been gradually uploading some of his clips to YouTube, the 'Fraserburgh on Film' research project goes beyond the storytelling limitations of the video streaming platform by providing a space for the presentation of mixed media, utilising the many methods available to the digital storyteller to convey a story (Sage et al. 2018). The materials recorded by James Taylor do not all deal with the North-East Scotland. However, as this research was concerned with Fraserburgh and the surrounding areas, a selection of his films were viewed and sorted for geographic relevancy with materials chosen which dealt with people and content relevant to Fraserburgh and the villages in close proximation to the town.

The selected films were then digitally enhanced and edited before being uploaded to Vimeo, the chosen video hosting platform for the clips as it allows for an advertisement free premium subscription service with advanced embedding features which were necessary when linking the video content with the platform. Adobe Premiere Pro was utilised to edit the clips and to rectify a number of audio and visual issues which arose in the analogue to digital conversion process.

As Smimite et al. (2013) observe, audio of a low quality can negatively impede the way in which an individual relates to, and consumes, an audio-visual artefact. As the research was connected with the representation of oral histories, it was important that audio tracks were presented in such a way that problems with noise or synchronisation with the video track did not hinder user experience of the content.

Each film clip was imported to Adobe Premiere Pro and, where necessary, edited to improve overall quality. The audio was cleaned up by taking 'noise prints' of unwanted hiss frequencies which were then analysed and reduced using Adobe Audition and where the audio track had slipped out of synchronisation, this was manually rectified. Video tracks which suffered from tracking issues caused by analogue hardware capture were digitally processed and stabilised with colour correction applied where issues with white balance and degradation of film occurred. 
A number of other films obtained from various sources were gathered for use within the research. Fraserburgh Heritage Centre had a small quantity of pre-digitised content which they granted permission to use. These also underwent the process of editing and colour correction mentioned above. However, due to the digitisation process used, the resolution of some of the clips was quite low but they were still included within the archive as many of them represent important elements of the social and cultural fabric of the area.

A small amount of $8 \mathrm{~mm}$ film shot by residents of the town was also obtained and digitised for use within the project. The majority of this came from Edith Burrows, whose father, George Rattray, owned a shop on High Street and was a keen amateur film maker. In order to digitise these, an $8 \mathrm{~mm}$ projector was used in conjunction with a telecine box and the projected image was recorded on a DSLR camera through a macro lens. The frame rate of the camera was altered so that it could match the 18FPS of the $8 \mathrm{~mm}$ projector.

\section{Audio recordings}

A series of audio recordings were made to enhance to the content on the portal and to provide a modern perspective on stories from the past. These came in the form of short anecdotes from James Taylor about some of his interviewees, commentary from Edith Burrows of her father's films as well as snippets from interviews conducted with actors Bridget McCann, John Buick and Fiona Knowles who appeared in televised versions of James Duthie's plays and were contacted to provide reminiscences as part of the research. In including these, a dual perspective (metalevel local history reminiscences) on some of the stories was created.

\section{Newspaper clippings}

Various newspaper clippings, obtained from the British Newspaper Archive, were gathered, mostly from the archived versions of publications from the North-East of Scotland, namely The Fraserburgh Herald and Northern Counties advertiser, The Aberdeen Press and Journal and The Evening Express. Scans of the pages were edited using Adobe Photoshop to clip the relevant content, which was then uploaded with metadata attached, detailing origin of the clipping, publication date and copyright information. 


\section{Creating the portal}

It was decided that a clean and simple aesthetic design for the portal should be adopted which would lend itself to the collated materials being emphasised while maximising functionality. The result was the creation of a space which is intuitive in its user interactions and simple to navigate. Squarespace was used as the platform for creating the portal and although elements were borrowed from their pre-set templates, a unique layout for the site was developed using elements of CSS coding. This was utilised in creating the 'behind the film' section where a 'fade in' was coded for each page as well as removing the site navigation banner in order to allow the content to fill the browser screen.

\section{Creating the archive}

At the launch, the archive contained 90 unique catalogue entries each containing a film clip linked from the content uploaded to Vimeo. In order to create uniformly-presented entries (that can be easily updatable with subsequent information and tagged with appropriate metadata), it was decided that a modified version of the Squarespace 'blog' function be used. Each 'catalogue' record in the archive is, therefore, essentially a 'blog' post which has been slightly modified to closer resemble a more traditional archive record.

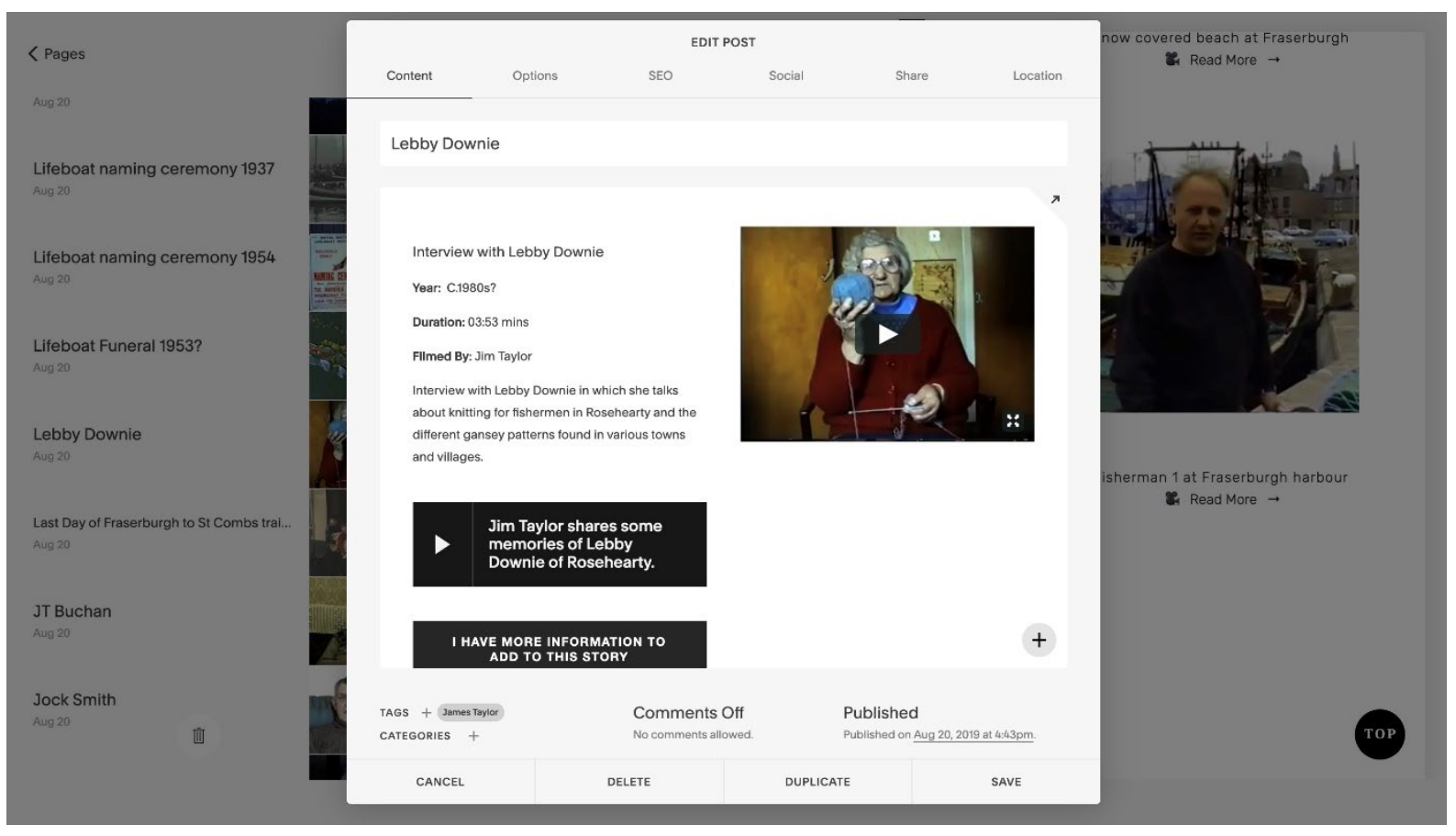

Figure 1.

Gathered film content was viewed and analysed for emergent themes which were then in turn used as the basis for tagging entries with metadata. This permitted the indexing of film at the 
appropriate place within the archive. Fig. 2 shows the tag as applied to the entry for the purposes of indexing, which in this instance is 'James Taylor', the creator of the content.

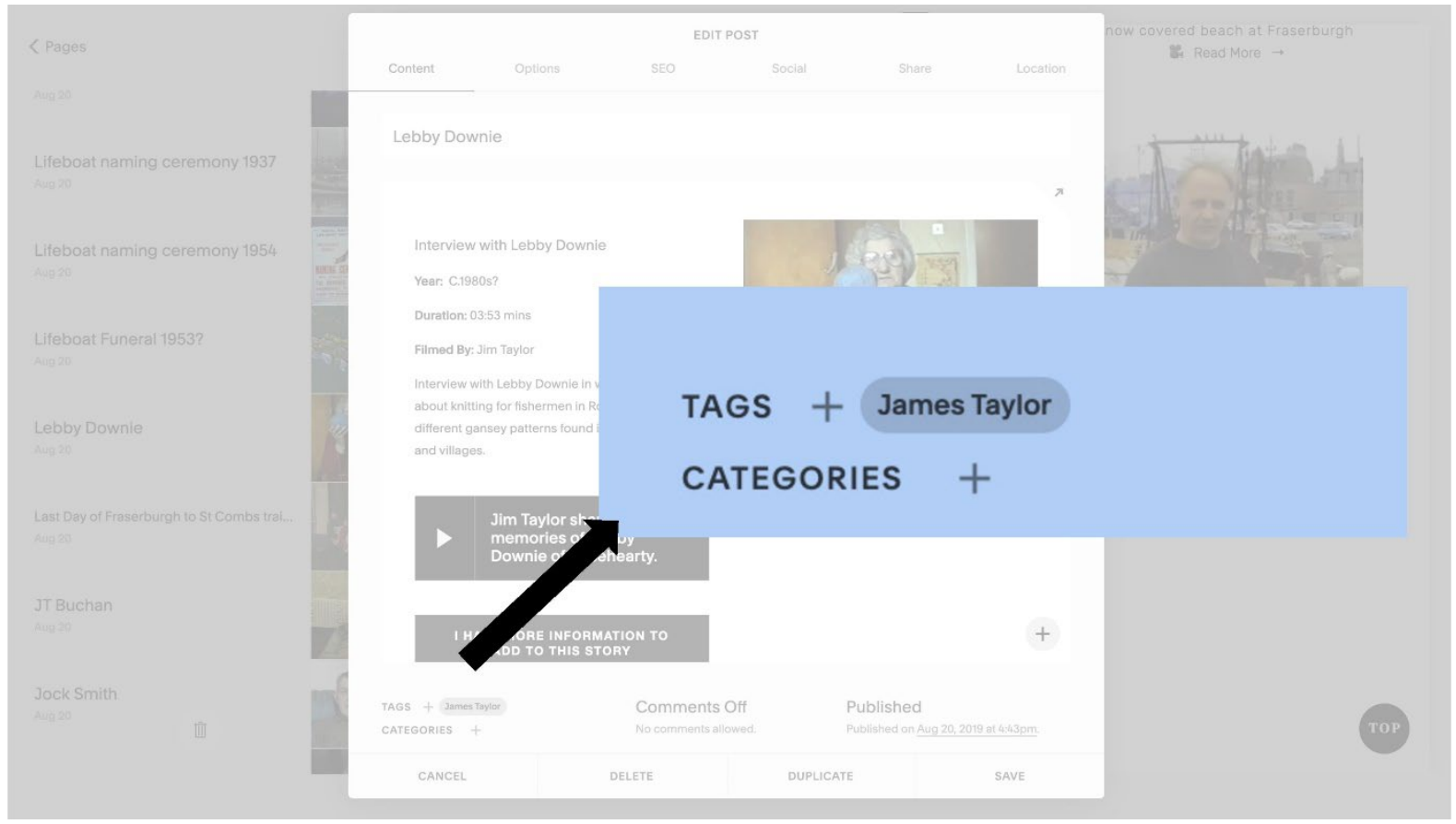

Figure 2 .

Used in conjunction with the archive section, the tags can be used to index content. As seen in fig. 3 and 4, the 'James Taylor' tag is used to index the entries under the correct heading. In using this function, the creation and indexing of further records is simplified so subsequent entries can be added with relative ease as the archive progresses after launch.

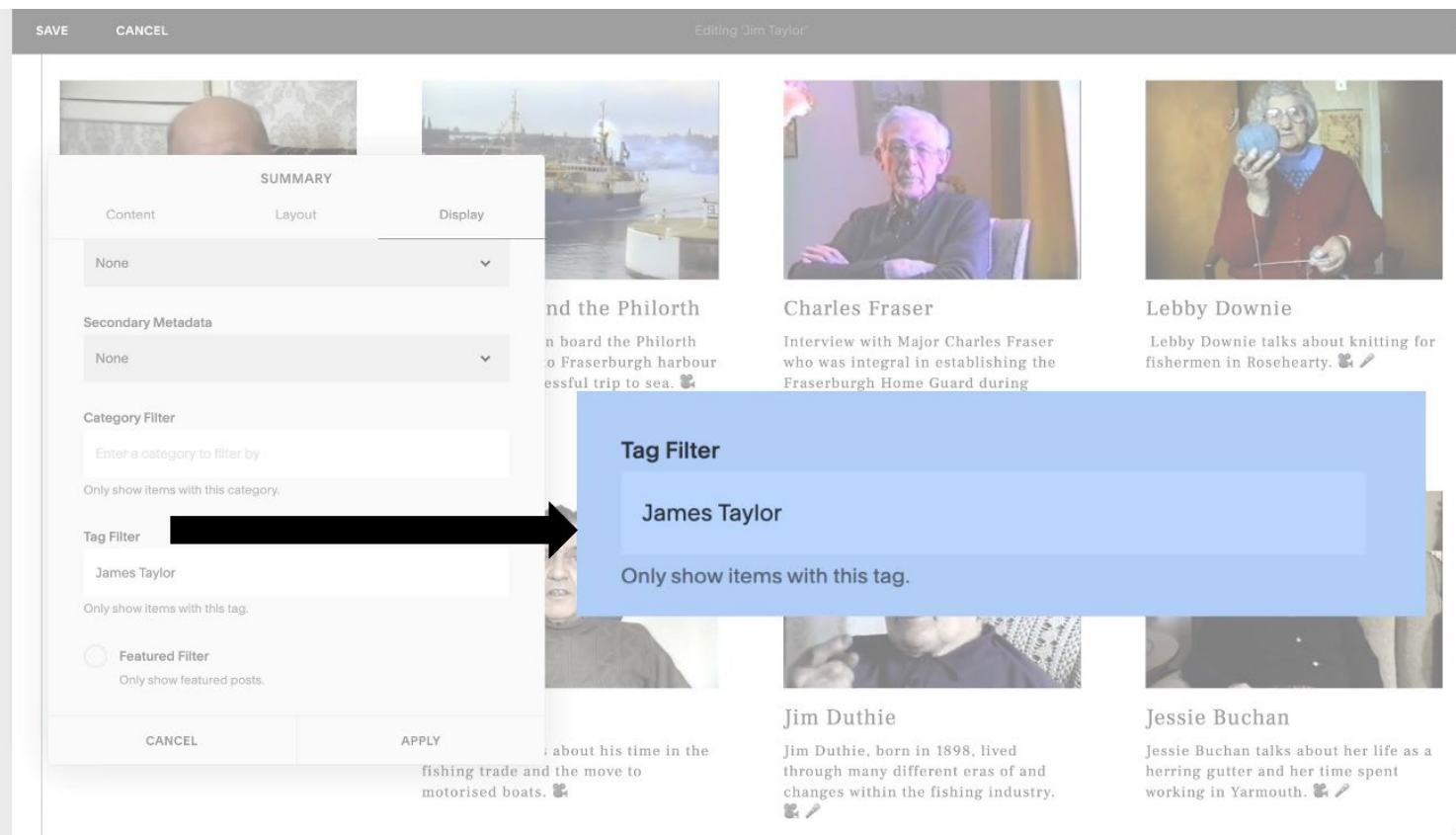


Figure 3.

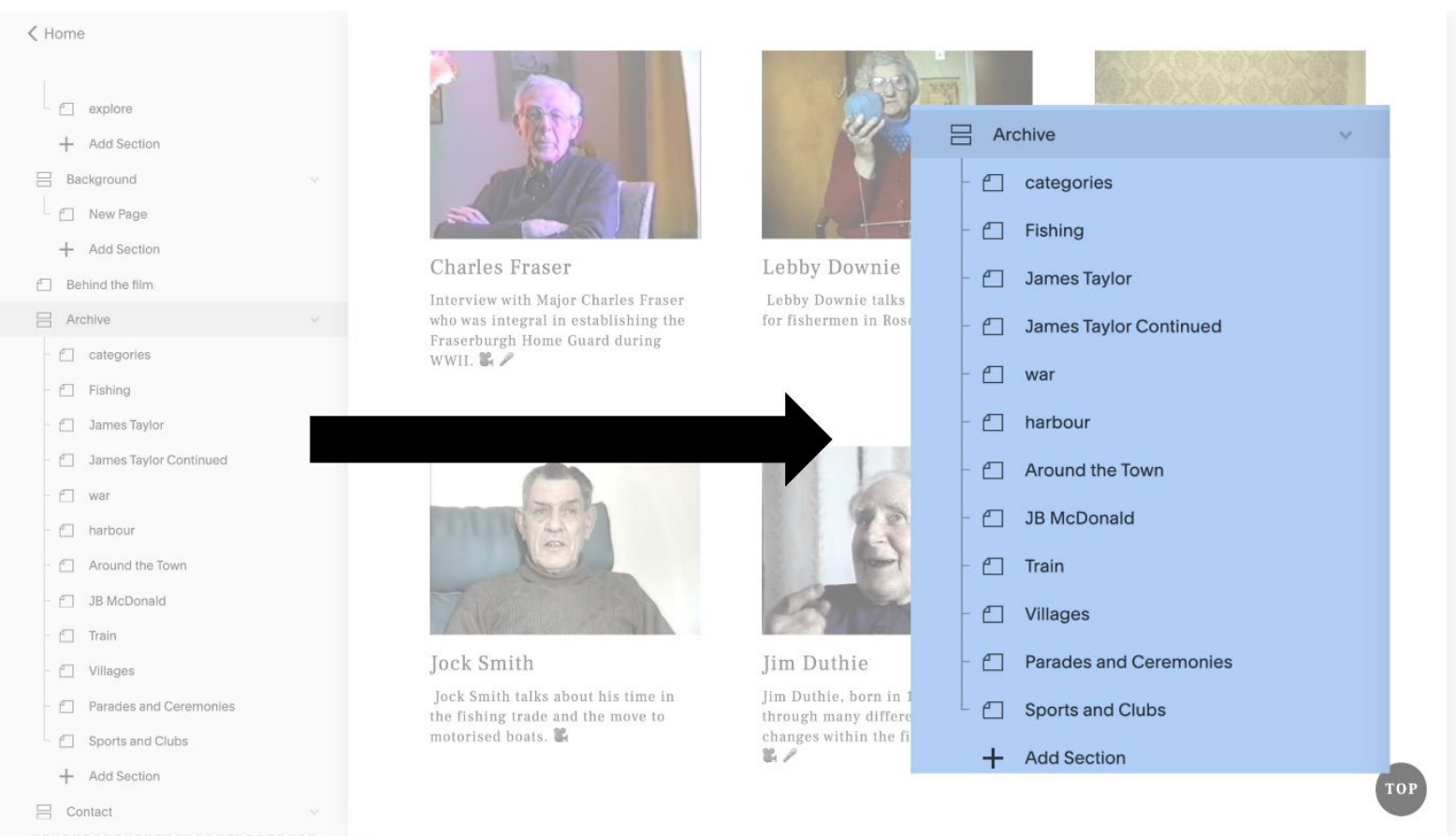

Figure 4.

Further metadata tags were also added to entries which served to improve the search function of the site. Subject matter was deduced from the notes taken on videos and subsequent relevant tags added to assist users in finding desired content. Although archiving and metadata standards do exist with the General International Standard Archival Description (ISAD), these were not strictly adhered to as many of the predicted search terms are considered to be unique to the locality, such as names of places or people. Techniques were deployed, however, which allowed content to have enhanced discoverability through the techniques offered by metadata descriptors (Labrador and Chilton 2009). The resulting search function is suitable for the nature of the site, which although sharing similar aesthetics with a traditional archive catalogue, functions in a slightly different way.

For example, as shown within fig. 5 and 6, by adding the tag 'Rosehearty', to the film of Leeby Downie, a one-time resident of the town, the search function will produce a relevant result 
when searching with this term.

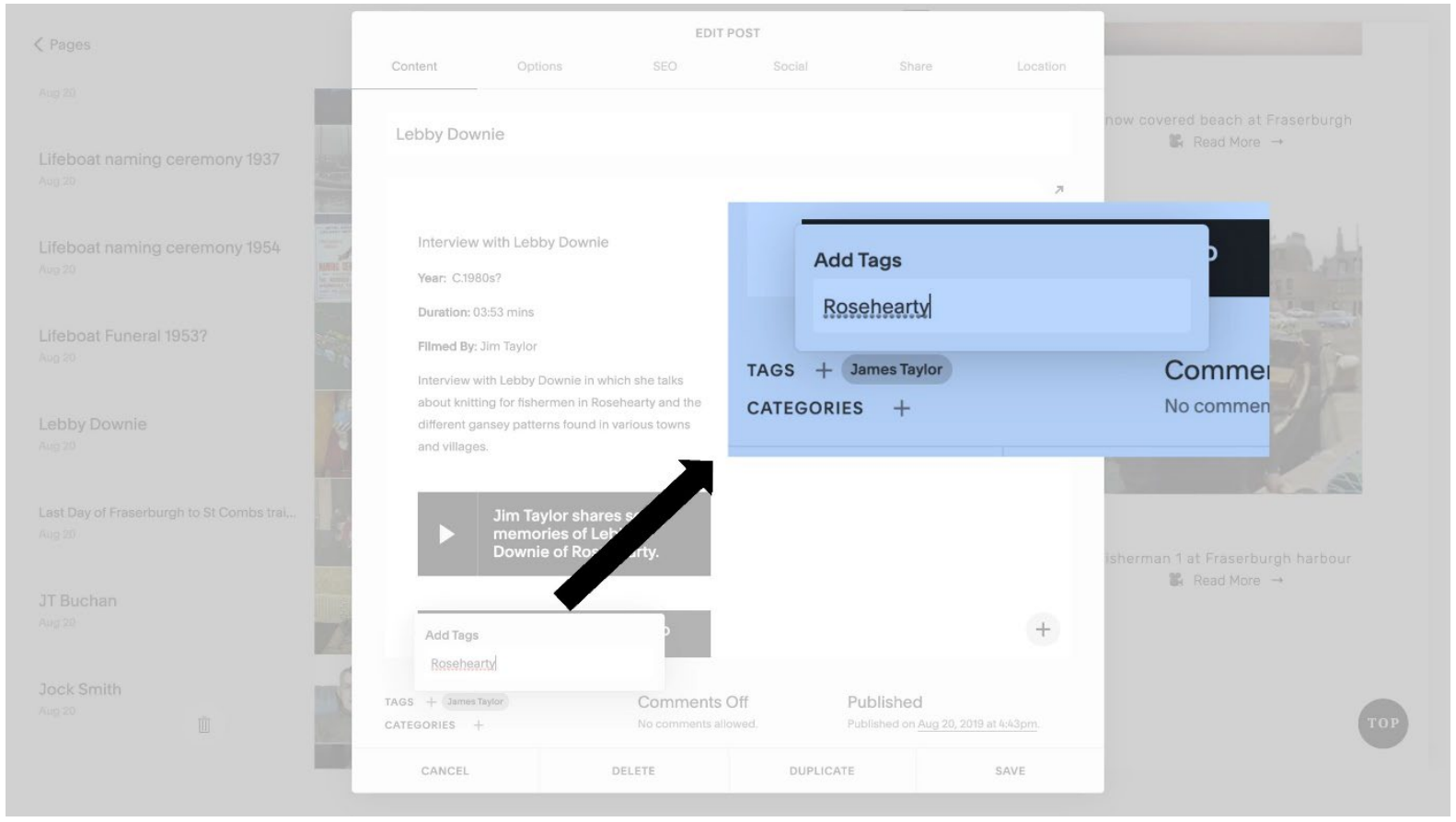

Figure 5.

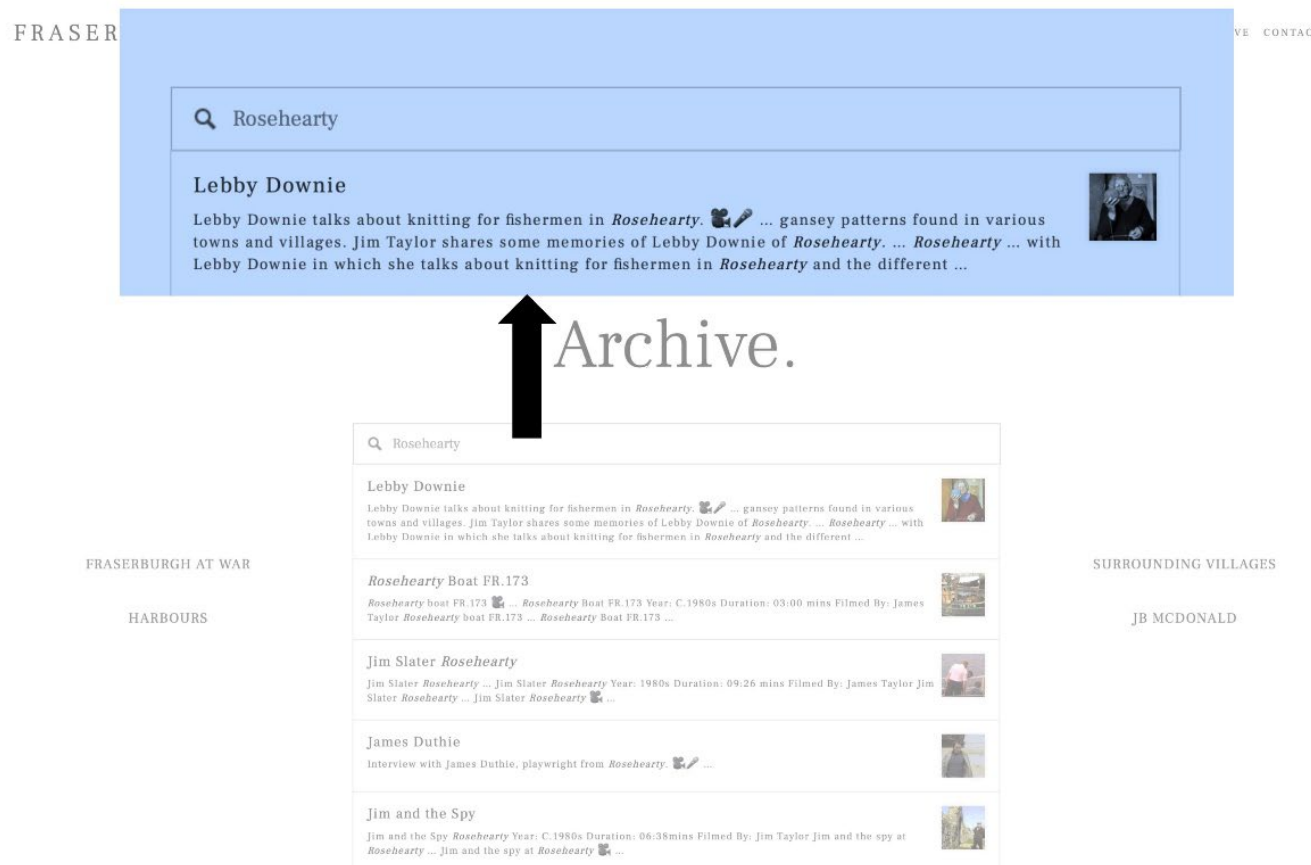

Figure 6.

A number of tags were added using this technique, taken from themes and keywords which emerged from performing a content analysis of the clips within the archive. 


\section{Methodological reflections}

In adopting these methods and techniques, a platform was created which echoes a traditional archive but allows for the dynamic use of gathered materials across the site. In using indexing and metadata tagging in ways mentioned above, the platform has been made flexible and easy to update as new information becomes available which, in turn, facilitates the desired outcome of the project having the ability to grow and develop over time.

Archive Aesthetic Design

FRASERBURGH ON FILM

HOME BaCkground Behind the FLLM ARChIVE CONTACt

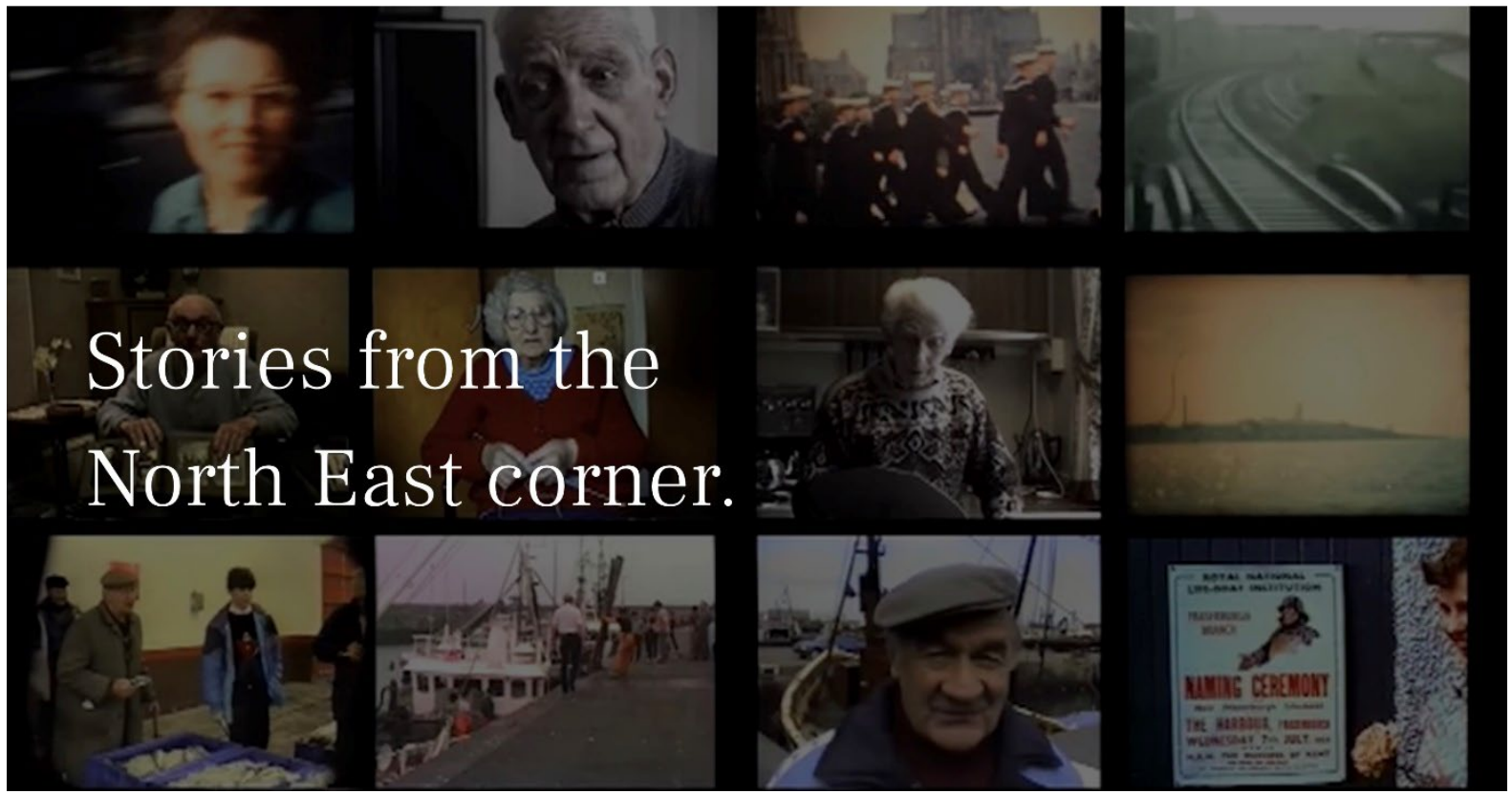

Figure 7

When planning the portal, several decisions were made in relation to the design and functionality of the site. It was decided that in order to highlight the collated materials, that a minimalistic approach be adopted which would in turn lend itself to the creation of a userfriendly design. As acknowledged by Rossiter and Garcia (2010), digital platforms have the ability to distract from the story if presented in overly complex manner with unintuitive navigation and functionality. Artese, Gagliardi and Ciocca (2017) agree with this sentiment and propose that, in the context of social and cultural websites, some of the key aspects to consider when designing a platform are interactive features, aesthetics and site architecture.

With ease of use and navigation in mind, the research focused the collation of materials via two main areas in which the collected artefacts of intangible heritage can be consumed: the 'archive' 
and 'behind the film'. The former provides an interface where users can search and interact with content freely and is based on a design of a traditional archive or online catalogue. The 'behind the film' element of the project provides a more curated experience for the user, guiding them through narratives borrowed from the themes of selected films, supplemented by additional artefacts of digital ephemera such as documents and newspaper articles as well as audio recordings and digital imagery.

\section{The archive}

FRASERBURGH ON FILM

home background behind the film archive contact

\section{Archive.}

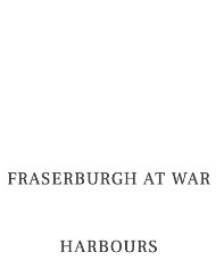

HARBOURS

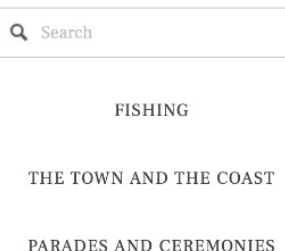

PARADES AND CEREMONIES
JIM TAYLOR FILMS

TRAINS AND RAILWAYS

CLUBS AND ORGANISATIONS
SURROUNDING VILLAGES

JB MCDONALD

Figure 8.

The archive is arranged in such a way that, alongside a traditional search function, anchor links have been used to assist the user in navigating the space. As seen in the screenshot above, the anchor links shown below the search function correspond to the broad themes which emerged when gathering the films for use within the portal. The archive content is presented as a long form single page, so these links allow the user to be quickly taken to their desired section on the page. Although it appears to the user that the archive is one single page, it is in reality made up of 10 index pages, each with a collection of individual records (in the context of this work, the unique page created for each film) automatically indexed in the relevant section via the attachment of metadata tags. Arranging the records in such a fashion follows suggested recommendations of best practice when designing an archive where accessing content should not be an over complex process for the user (Maxwell 2010) and expansion be facilitated as new materials are collected. Considering that an aim of the research was to use the platform as a tool for participatory heritage, where user input and content production is seen as a vehicle for 
collection expansion (Tasker and Liew, 2018), the architecture of the archive was designed in such a way that this would be easily achieved.

The search function and anchor links are used solely to assist in navigation of the space and not to restrict the user's interaction with the archive. Therefore, normal scrolling of the page has also been included which overrides the functionality of the links.

Fishing through the years

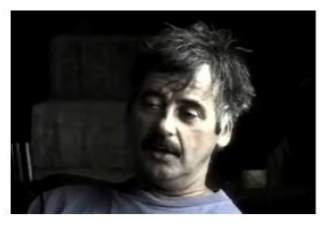

Willie Tait

Interview with Willie Tait

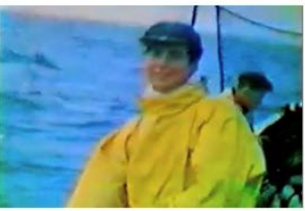

Unknown fishing video Unknown fishing video

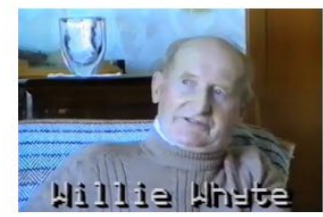

Codling Willie Whyte at home

Interview with Codling Willie Whyte
filmed at his home.

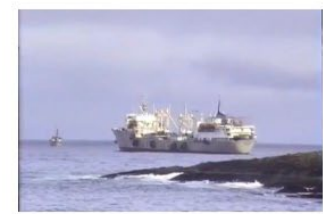

Russian Factory Ships

Footage of Russian ships off the coast Footage of Russian ships off the coast
of Fraserburgh shot from Broadsea and a trip on board, leaving from

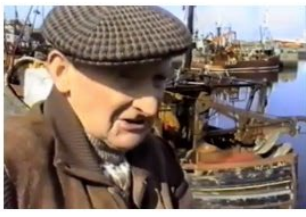

Codling Willie Whyte Interviews with "Codling" Wille Whyte
filmed at Fraserburgh harbour.

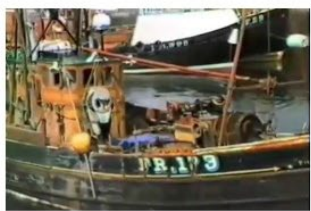

Rosehearty Boat FR.173 Rosehearty boat FR. 173

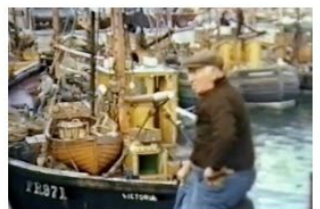

Victoria

Victoria JB McDonald

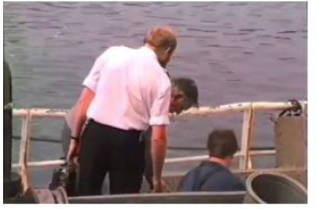

Jim Slater Rosehearty

Jim Slater Rosehearty

Figure 9.

The user is presented with a screenshot, title and brief description of each catalogue entry. The use of symbols has also been included to signify to the user the types of content present within each record: the camera symbol (an) denotes the record contains a video clip, the microphone (ڤ゙) that the record also contains a supplementary audio recording and the newspaper icon (国) to signify that the record has an artefact of digital ephemera attached such as a scan of a related newspaper article or text-based document.

Upon clicking on the entry, the user will be taken to the full record (fig. 10) which contains a more detailed description, the full-length video clip available to view, and in this example, an audio recording from James Taylor reflecting on his relationship with the subject of the interview, Willie Whyte, reminiscing about the time he filmed the featured interview. 
Interview with Codling Willie Whyte

Year: C.1980s

Duration: 07:00mins

Filmed By: Jim Taylor

Interview with Codling Willie Whyte filmed at his home.

Within interview, Willie Whyte talks about his early days growing up as a child in Cairnbulg as well as his first experiences of his life aboard fishing vessels in North East of Scotland.

Willie Whyte came from a family of fishermen, and the Whyte family continue to be involved with the industry to this day

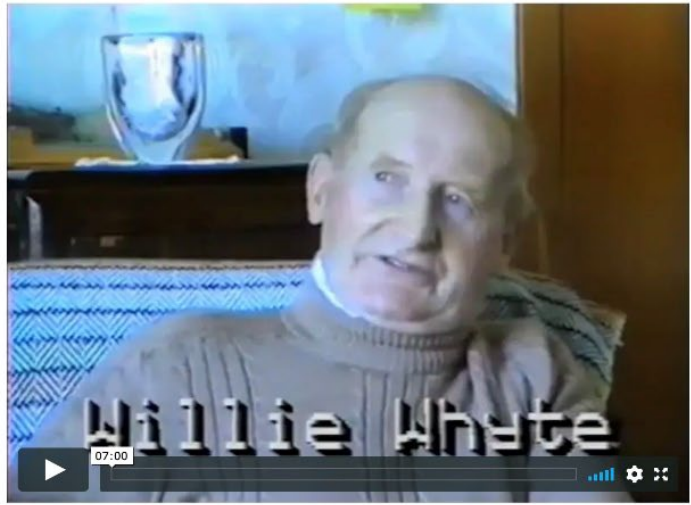

Jim Taylor talks about meeting Codling Willie

Figure 10.

Users are actively encouraged to contribute any further information they have which is related to people featured or stories conveyed within the platform. Each record has a simple to use feedback function allowing comments and information about films from the community to be sent directly to admin. An aim of the work going forward is to record more audio clips featuring modern reflections from people about the films and subject matter featured so contact will be made and contribution encouraged in this way.

Although it was possible to add the functionality whereby users could add their thoughts directly to pages instead of going through site administrators, it was decided that interaction in this way was not in keeping with the overall desired outcome of the research where a curated experience is provided. In linking with the social media platforms Facebook and Instagram, the functionality will be provided whereby users can comment directly in a more familiar setting. Moreover, as with other materials presented within the project, contributions from users will have their value celebrated with any quotes, audio recordings or photographs obtained through this method being used in a way which seamlessly incorporates them into the website to further enhance content. 


\section{Behind the film}

Although the archive allows for the use of additional materials which enhance the content of films and interviews, it was decided that the platform could also deploy methods of digital storytelling in order to create a narrative driven backdrop to some of the stories presented within. Rizvic et al. (2017), when developing guidelines for effective interactive digital storytelling, concluded that materials in a variety of formats should be presented in order to retain the attention of the audience and that the information should be presented in such a way that the user finds ease in navigation.

Initially when designing this section of the portal, an alternative format was adopted where information was presented in a traditional 'long scroll' page. However, upon conducting some early user functionality tests, it was found that users would often scroll past some of the collated information and reported feeling overwhelmed with material on some of the longer sections.

Again, when referring to the digital storytelling guidelines developed by Rizvic et al. (2017), presenting too much information which is poorly structured discourages users and diminishes their motivation to explore. With this in mind, the format of the section was changed and simplified considerably with the aim of achieving the following: $a$ ) to limit on screen distractions and focus the user's attention on the materials being presented and $b$ ) to deliberately slow down site navigation to encourage users to take time to read and interact with the conveyed narrative.

The chosen format for this section borrows elements from an interactive exhibition piece, taking the user on a guided journey which has the "capacity to engage in multiple forms of multimedia content, such as image, audio, video [and] text" (Dumitrescu, Lepadatu and Ciurea $2014 \mathrm{p}$ 103), beyond the restraints of a physical museum space. 


\section{Behind the film.}
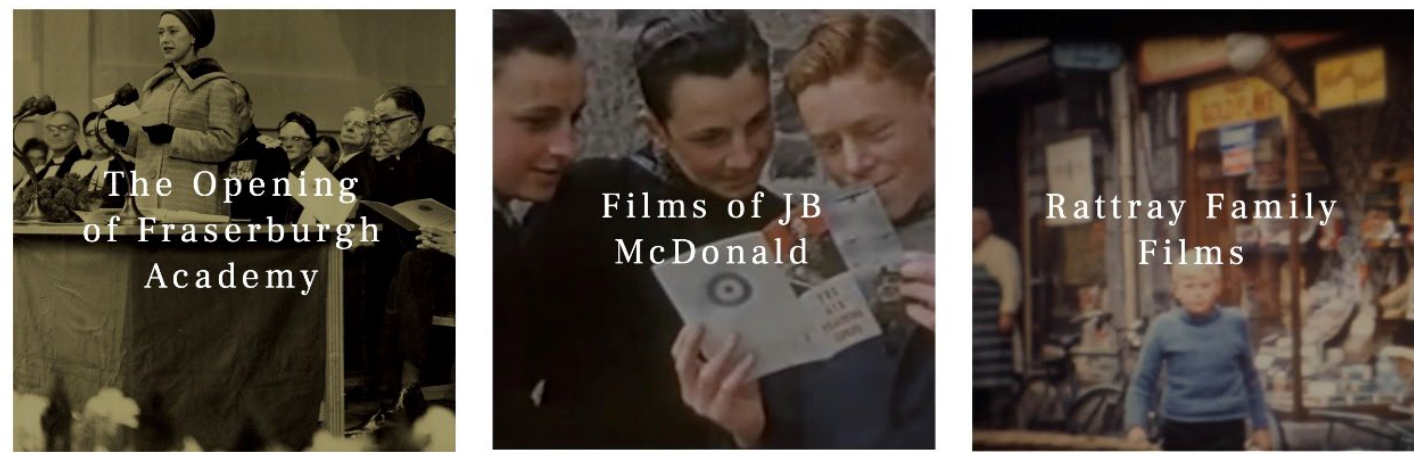

Figure 11.

\section{Sample functionality}

Upon arriving at the 'behind the film' section of the site, the user is greeted with the landing page as seen in fig. 11. Each picture represents an expanded story on a certain topic. Upon launch, the site will feature twelve of these sections with the aim of adding more as part of the ongoing development of the archive.

One of the stories dealt with within this section is that of James Duthie, a playwright from the village of St Combs. A one-time deck hand and cook upon a fishing boat, he made an unexpected career change in the 1970s, following his desire to become a writer for the stage and screen. James Taylor interviewed James Duthie at his home in the late 1980s and the full-length interview, with a run time of at 31 minutes 49 seconds, is available to view within the archive. However, the 'behind the film' section of the portal has facilitated the expansion of certain details contained within James Taylor's film and allowed the interview to be broken down and presented in shorter sections dealing with particular details of James Duthie's story. This is in keeping with recommendations from Rizvic et al. (2017) that suggest that the length video segments be kept short when used within the process of digital storytelling as user attention spans often lead to longer clips being overlooked. 


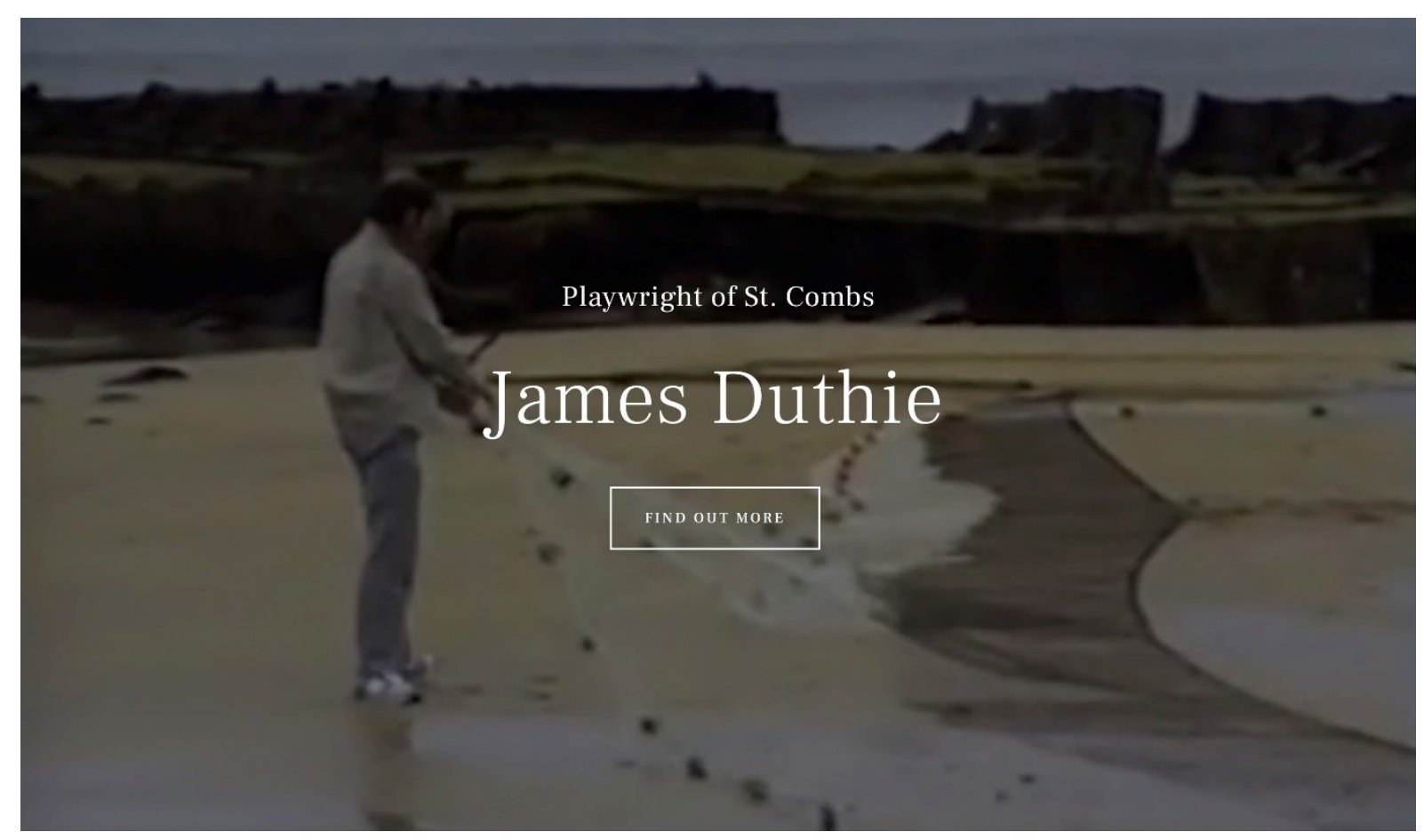

Figure 12.

Each section has an intro page similar to the one shown in fig. 12 where a full-size video plays behind the title on a loop and serves as an introduction to the story. As can be seen from the screenshot, the navigation banner used elsewhere in the site has been removed so the content is displayed full screen.

The user is then guided through the story page by page with a curated narrative about the topic in question presented. Fig. 13 demonstrates that the top navigation has been completely simplified and content deliberately displayed on a single page which cannot be scrolled, imitating a digital presentation or interactive exhibition piece, focussing the user without distraction on the content itself. In this example, an audio recording from James Taylor, in which 
he describes conducting the interview with James Duthie, is provided on the first page.

previous

James Duthie, a one time cook on a fishing boat, made a change of career in the 1970 s to become a playwright, writing material for television and screen. Notable successes of his career were 'Donal and Sally' (1978) which was produced by the BBC under the 'Play for Today' series, 'The Drystane Dyker' (date) produced by BBC Scotland and the stage production 'Greta' (1997).

The interview featured within the archive was filmed by Jim Taylor at James Duthie's home in St. Combs.

Jim Taylor talks about meeting James Duthie
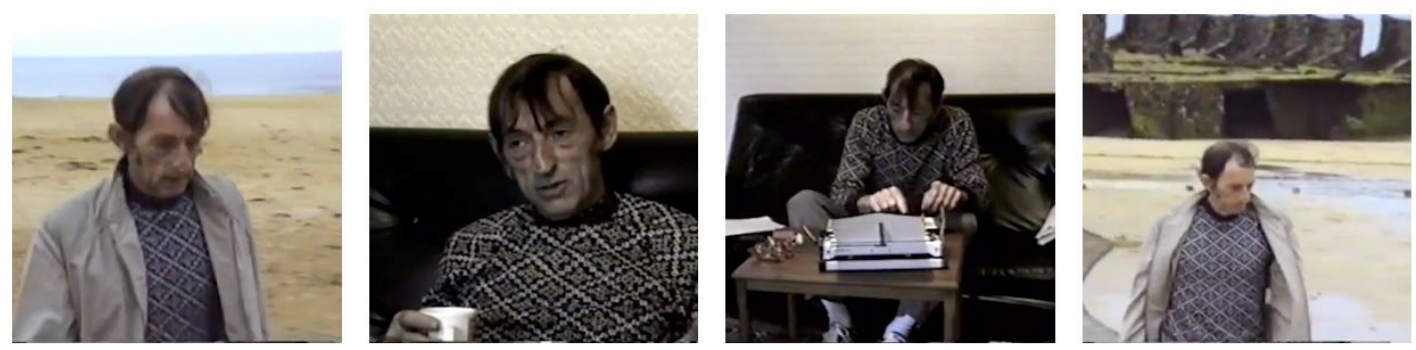

Figure 13.

Examples of Duthie's work are presented in chronological order within this particular 'behind the film' section, with supplementary archive materials used to further enhance the story. His first play, 'Donal and Sally', was produced for screen under the BBC's 'Play for Today' series and, as seen in fig. 14, a clip of the interview in which he talks about the play has been edited so it runs at a more digestible length of 2 minutes 17 seconds, serving as an introduction to this aspect of his work. 
Donal and Sally (1978)

While working on a trawler out of Peterhead, James Duthie saw a BBC production being filmed while on shore in Shields. It was here, while talking to the producer on set, that he was inspired to pursue the long held aspiration he had of becoming a screen writer. Within the interview with Jim Taylor, James Duthie talks about how he feels he received his real education in the Picture House in Mid Street, a place he admits he would sneak in to through the toilet window. This early interest in film resulted in a life long dream of becoming a writer for the screen.
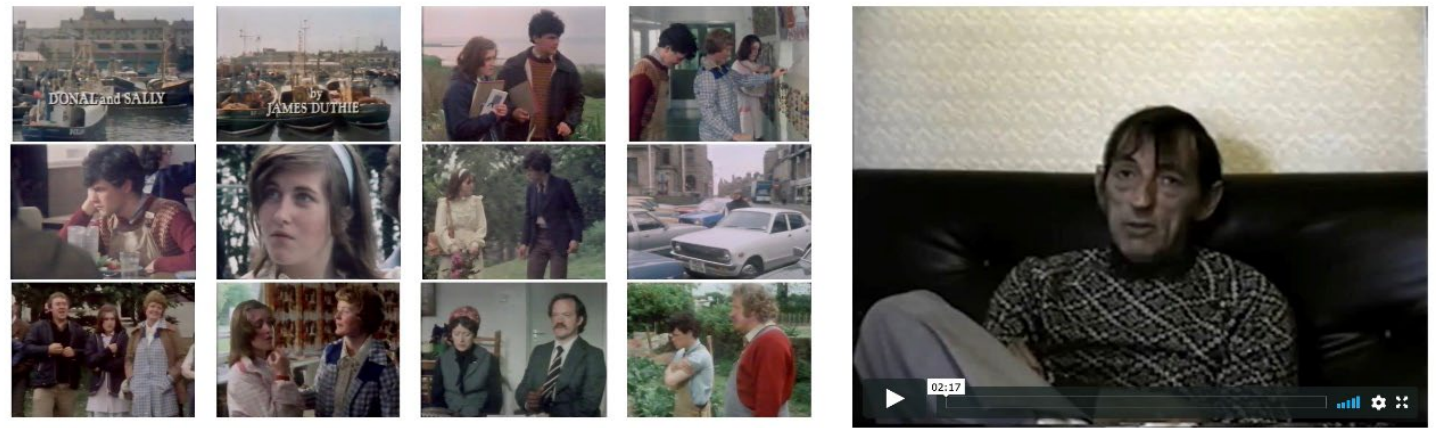

Figure 14.

As the user continues their journey through the narrative, they are presented with other materials which add further value and context to the story. A typical example contains a combination of materials to enhance a particular element or idea. Fig. 15 illustrates this with the page featuring an audio recording from Bridget McCann, an actor who featured in 'Donal and Sally', as well as screenshots from the play, an archived newspaper article about her involvement as well as a short clip featuring her in the play itself. 


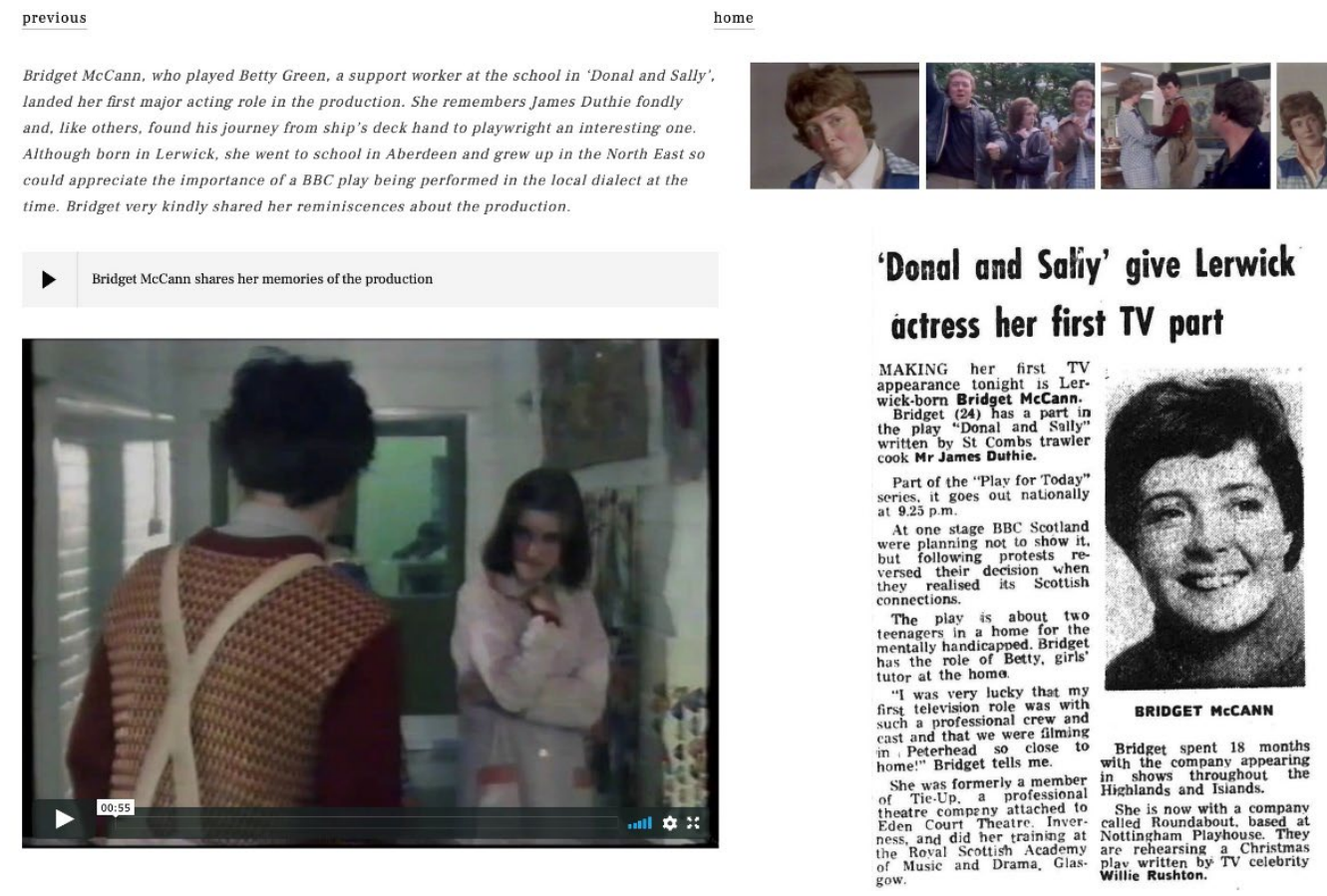

Figure 15.

Other curated sections featured in the 'behind the film' section feature audio recordings of reminiscences from local people, scans of advertisements and historical documents and photographs which again serve to enhance the content of the collated films and place them in context for the user. As with the 'archive' section, users are encouraged to get in touch via the 'more information' button, which will allow them to offer additional information presenting the opportunity for community input in the process of collection expansion.

\section{Launch and impacts}

The Fraserburgh on Film archive was launched on 2 December 2019. It rapidly fulfilled the desired outcome engaging users with the social and cultural history of Fraserburgh and its surrounding areas through the presentation films and digital materials. As of June 2020, six months after launch, the online archive has had over 53,000 page views with collective viewing numbers of film clips reaching over 85,000 . The project was also featured on a Scottish Television news report ( 2 Feb 2020), the film of which itself was viewed over 17,000 times within the first month of launch 


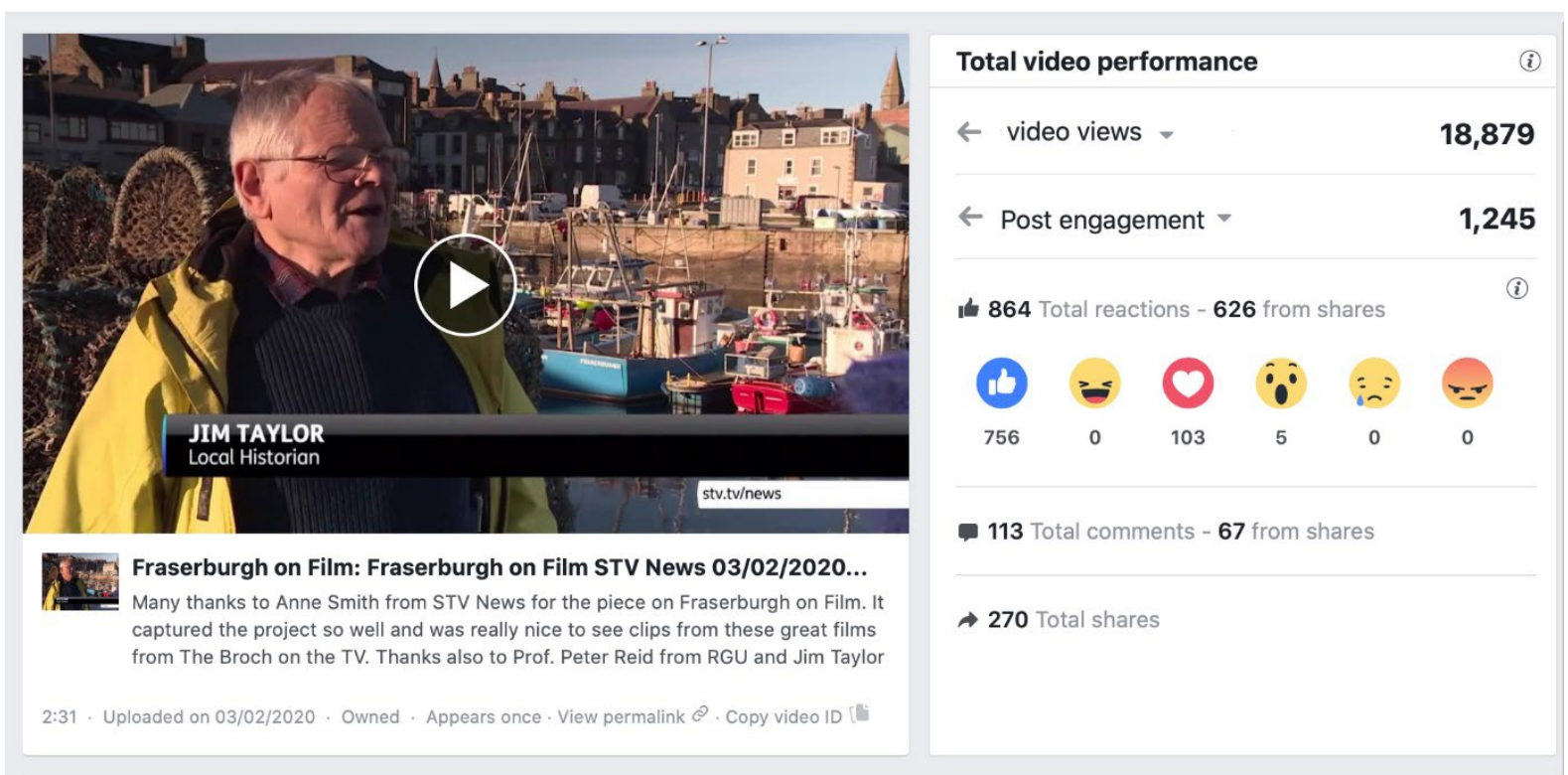

Figure 16.

As mentioned earlier, a key aim for the archive is that it be used as place to foster community involvement, inspired by the theories of participatory heritage to "draw individuals together around content" (Roued-Cunliffe and Copeland 2017 p. 1) and offers members of the online community an opportunity to be part of the story being told instead of passively consuming content (Owens 2013).

In order to support this element of the research, accompanying social media pages have been created on both Facebook and Instagram to act as a place to promote new material as it is added to the site, encouraging return visits. In addition, it has further enhanced user connectivity and interaction with the site, stimulating participation by eliciting information to supplement details surrounding events seen within the films as is demonstrated in the figure below.

In linking with social media, users have been given the opportunity to add reflections and engage with content and the potential for collection of further sources of information for the portal has been realised. Crowdsourcing of data and gathering user generated content can facilitate the act of connecting with heritage while providing a valuable outlet for collection expansion (Ridge 2013). In the context of this project, since launch, private film collections for inclusion have donated been from a number of individuals. These include a series of films from the 1960s of boat launches and events around the town and a series of films shot in the late 1930s by Alexander Benzie, a well-known business owner from the era, which were submitted by his grandson and previously only viewed by his close family. This form of participatory engagement highlights the potential of unlocking hidden (often private family) archives. The Benzie example also reinforces the key aspects often observed in local participatory heritage, 
from the relatively prosaic comments about locations through to the visceral and deeply-held affection for a place or a person.
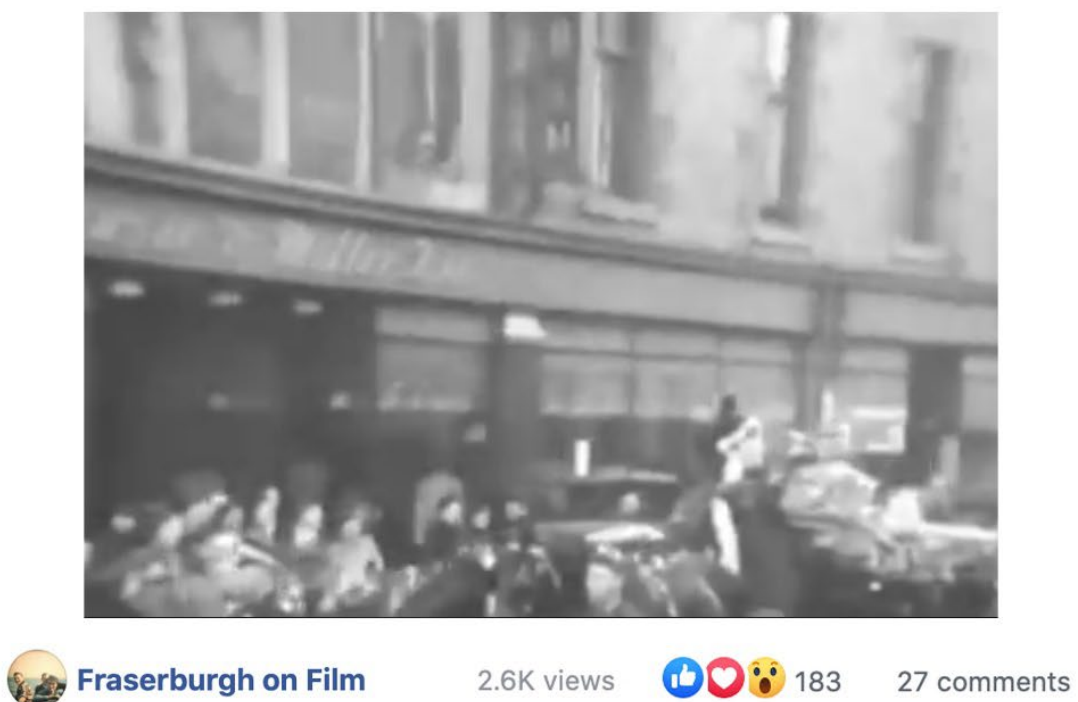

Excitement on Mid Street in the late 1930s as Santa (or as he is better kent in the Broch, Suntie) arrives at Benzie and Miller's.

User 2 What a fantastic old film!! Benzie \& Miller had the BEST grotto, because you had to get on a trainie that seemed to take you on a wee journey before you got out to see Sunty!! It was soooo magical

User 3 a ken I loved at trainie, best Sunty journey

User 4 I loved the train thought I had gone a long way to see Santa

User 5 Used to love going to Benzies to See Santa going on the train and coming out the other end to Santa's Grotto it was great

User 7 Aw I loved going to see Suntie in Benzie and Millers' I would get a pencil case every time and brought it back to change it. It was downstairs and they had some kind of vehicle you went in to see Santa in his grotto. Lovely halcyon days those were! I was really happy.

User 8 was it where Maitland's is now or across from Congregational church?

User 9 it was across fae the congregational church

User 7 thanks couldn't quite work it out by the film but can remember being in it

User 12 It was a submarine I remember going in with the sea life floating past the windows. They probably changed it from time to time.

User 13 I remember that as well Moira and getting a Black Beauty annual fae Santa

User 14 Think they changed it fae year to year but do seem to remember a Submarine ina wie fishies at the windows

User 17 Brings back lovely memories. I remember going on the train to see Santa with my granny Ross User 18 Lots of memories of working at Benzies in the sixties.

Figure 17. 
User submissions of sources of information, reminiscences and reflections, ephemera and photographs have also been elicited through social media pages connected with the archive. Comments from the community have been added to film records in order to provide a modern reflective narrative to content, as the examples below show, helping to foster a sense of community ownership over shared heritage, placing the emphasis on a visceral nostalgia.
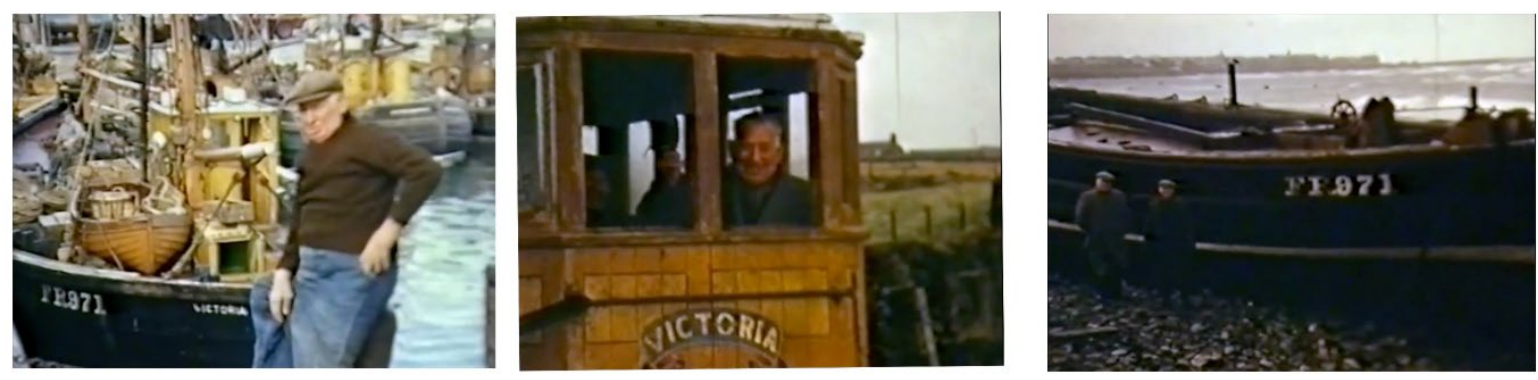

Victoria (JB McDonald) c.1960s

'This was my Great Grandfather's boat. She was the first 70ft fifie to come in to Fraserburgh and she was the biggest boat there in her time. She was struck by another boat, The Iris, and then towed to the breakwater to asses the damage but she was too old to repair and the damage was bad so she was patched and taken to Sandhaven to be be broken up. In the second part of the clip, you can see the patch on the boat as it sat on Sandhaven shore.

I now have a small boat named Victoria with the same number, FR971, named after my Great Grandfather's boat.' - Jason

Figure 18. 


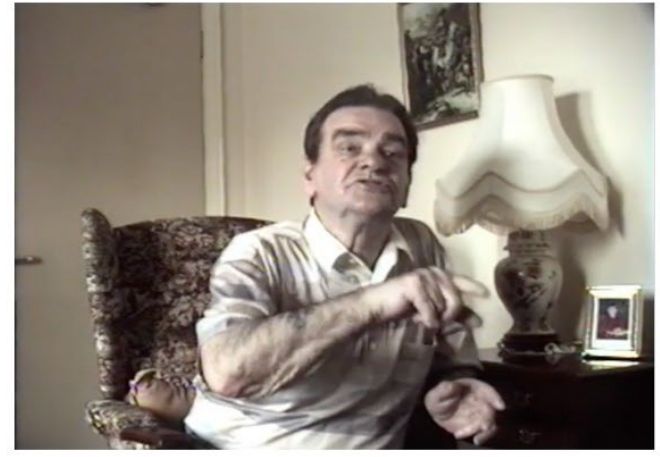

Interview with Jack Pressley (Jim Taylor) c.1980s

'I'm so moved by this film of Jack! Thank you . I used to have large family parties at Christmas and Jack came down. I last saw him Christmas before he died. He always called me Joycie.

Will tell my sister who is the widow of jacks son, Gene Pressley' - Joyce
Interview with Jackie Mackie (Jim Taylor) c.1980s

'My husband (Errol) was trying to get some footage of his

dad, Jackie Mackie who was a Gordon Highlander and prisoner of war. Someone told him this week they had seen it and there was an interview with his dad and some footage.

Just watched it. Brought a tear. Given me a lump in my throat. Errol will be so chuffed.' - Wilma

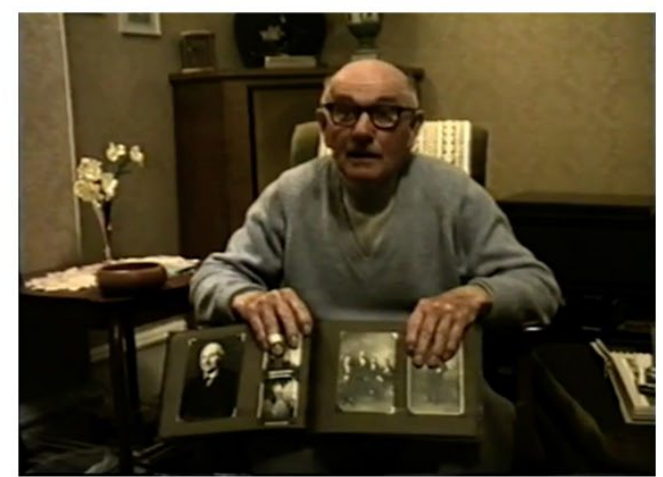

Figure 19.

Photographs taken at the time of events featured in the films have also been submitted by members of the community and have become stories in of themselves. These include the story of Andrew Noble who featured very briefly in Alexander Benzie's film the 1937 Coronation bike parade, as well as a photo titled 'The Three Queens', which showed Fraserburgh resident Marjorie Stephen, alongside Queen Elizabeth the Queen Mother and Queen Ingrid of Denmark in JB McDonalds 1956 film of the marriage of Hon. Flora Fraser and Captain Alexander Ramsay. These photos with attached information serve as personal vignettes taken from fleeting 


\section{glimpses of faces in crowds shot decades previously.}
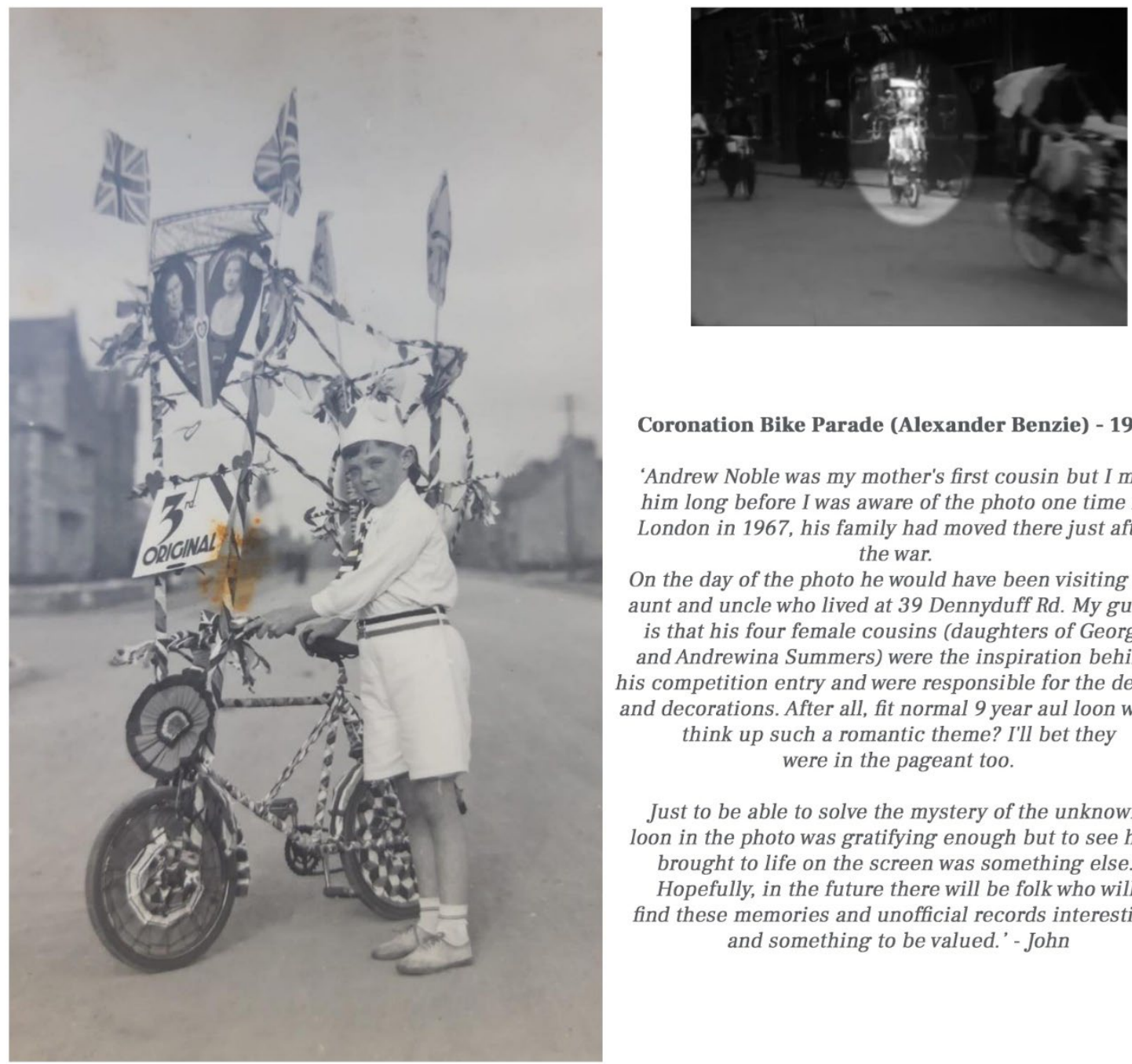

Coronation Bike Parade (Alexander Benzie) - 1937

'Andrew Noble was my mother's first cousin but I met him long before I was aware of the photo one time in London in 1967, his family had moved there just after the war.

On the day of the photo he would have been visiting his aunt and uncle who lived at 39 Dennyduff Rd. My guess is that his four female cousins (daughters of George and Andrewina Summers) were the inspiration behind his competition entry and were responsible for the design and decorations. After all, fit normal 9 year aul loon would think up such a romantic theme? I'll bet they were in the pageant too.

Just to be able to solve the mystery of the unknown loon in the photo was gratifying enough but to see him

brought to life on the screen was something else.

Hopefully, in the future there will be folk who will find these memories and unofficial records interesting and something to be valued.' - John 
Figure 20.
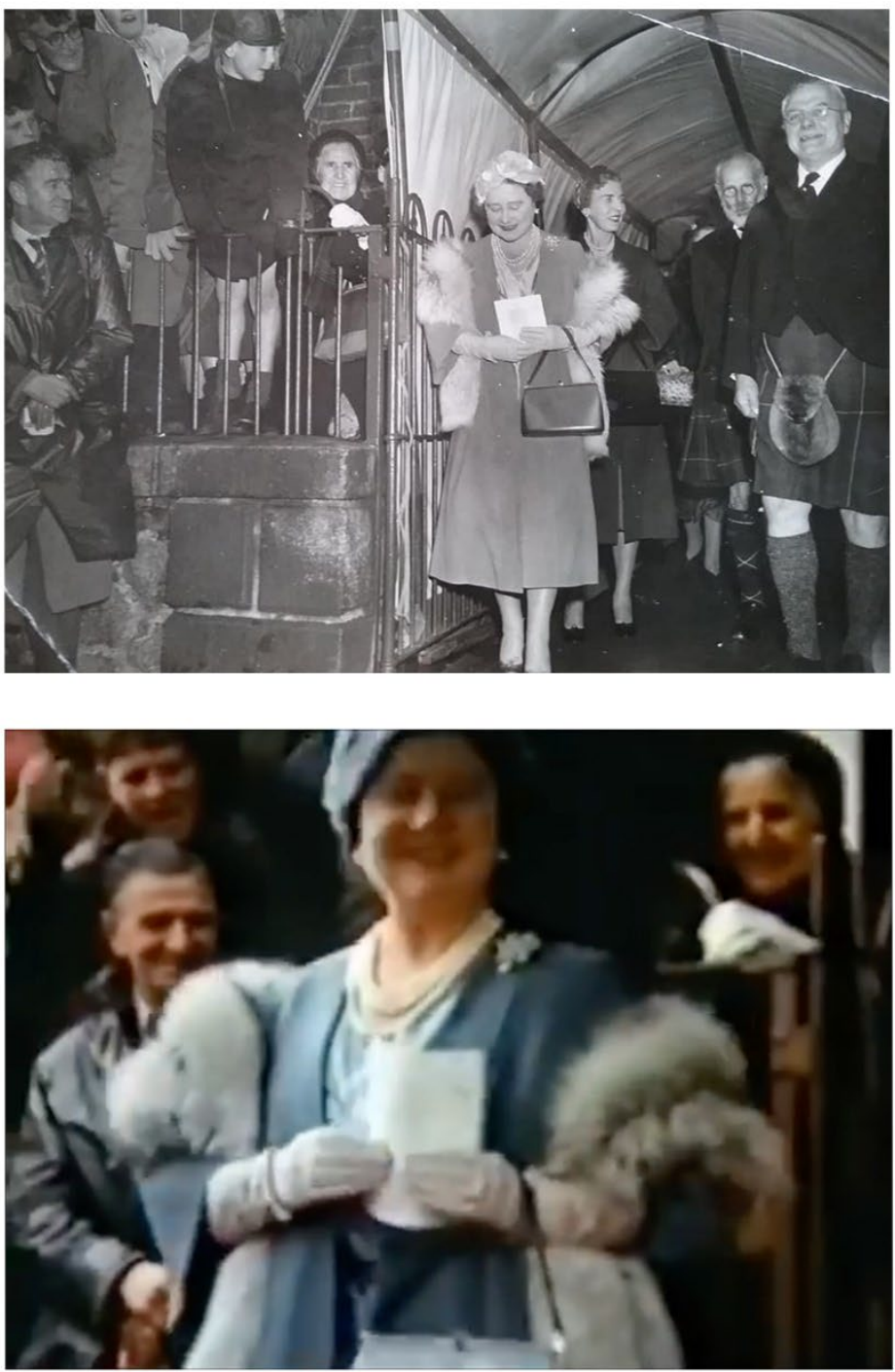

Marriage of Hon. Flora Fraser and Captain Alexander Ramsay (JB McDonald) - 1956

'This photo is known in our family as 'The Three Queens'. To the left of the Queen Mother stands Marjory Stephen, wearing white gloves for the special occasion. At the time she lived in Academy Road with her husband Wilson Stephen, retired coal merchant. She died the following year, aged 77.

Also, in the picture in a raincoat stands Connor Kay, the manager of Caledonian Cinemas.' - John

Figure 21.

As it stands, the content currently featured could be considered as first phase of a larger project, with the site having the potential to grow and develop over time. In creating a platform with mechanics which accommodate growth, development of the site is facilitated and will allow for the continued advancement of the aims of the project overall. Fraserburgh on Film presents an 
opportunity to foster the development of a community archive while helping to preserve the social and cultural lived histories and stories unique to the area. In doing so, the archive of materials has not only been preserved but their merit as valuable artefacts has engendered renewed pride within the community.

\section{Conclusion}

As detailed within this article, the various methods and techniques illustrated reflect the expectations set out in the aims and objectives of the research. The archive platform was successfully created and launched; it fulfils the intended function of presenting a series of curated films and digital materials, collating them in such a fashion that they reflect techniques of digital storytelling while engaging users with the social and cultural history of a town and its surrounding areas. In doing so, the content contained within films has not only been preserved but their merit as valuable artefacts, in which stories of the past are contained, has been celebrated.

In linking the platform with social media and encouraging community contributions within the site itself, the desired outcome of presenting the platform as a place to facilitate participatory heritage has been achieved. As previously stressed, growth and development are key desired outcomes of this research. By permitting this level of interaction and designing the archive of the project in such a way that continuous collection expansion is easily accommodated through the template design and functionality, the site created assists in meeting the overall aims and objectives.

On the surface, Fraserburgh on Film is an archive of moving image but when looked at it within the context of social and cultural history, it has so much more to offer. As a vehicle for community heritage it presents the opportunity to rekindle a sense of place in the area by providing a visual record of days and lives now gone; as a resource for local and heritage studies it provides a database of oral histories told in the words of local residents past and present; as a platform for participatory heritage it has the potential to bring members of the community together to create a lasting archive which documents their shared heritage. Its creation offers wider, transferable lessons for other, similar initiatives and projects. In particular, we would emphasise the importance of having (or at least developing) closeness to the community which undeniably yielded access to materials that might otherwise have remained out of reach.

The contribution made to the project by a single local historian, James Taylor, cannot be overstated. One of the unique things about the Fraserburgh area is that this vast archive of 
voices from the past exists due to his inexhaustible energy in documenting and preserving the stories and oral histories of the people who lived and worked in the region over the years. Other communities have similar, heroic figures. Although representing a small section of the body of his work, Fraserburgh on Film can act as means by which to further promote the significance of this collection, its value, and the unique story of the person behind it. Taylor's work could be said to be one of the motivations for this research and for finding ways to continue the story of the North-East by enabling archived materials to be viewed and accessed in one place for the first time and thus preserving the community heritage of an area, motivated by the drive to preserve the history of an area for its people.

The realisation of the platform as a resource for participatory heritage and the level of community interactivity will be enduring measures of the success of the project. In this respect, the creation of the digital platform is only part of the strategy that any organisation must adopt. It is the repository but in and of itself does not deliver community participation. With Fraserburgh on Film, that has been developed through social media which facilitates the sharing and wide dissemination of content, crowdsourcing of additional information and, indeed, the community's own sense of civic engagement and pride. The lesson for others in this is that the archive is important but it must be coupled with the kinds of the end-user community engagement that only social media can deliver. Considering that it is now said to be a crucial time for the preservation of deteriorating film formats and, given that digital manipulation of film has simplified its conservation, the project could work as a blueprint for similar initiatives in other parts of the country, encouraging the creation of community led audio visual archives. By establishing a visual archive to dedicated Fraserburgh and its surrounding villages, unique aspects of the lives of the people of the area can be honoured. In growing the archive with the help of the community itself, the narrative has the potential to develop, adapt and expand, continuously building upon the story of North-East Scotland. 


\section{References}

ALEXANDER, M. and HAMILTON, K., 2016. Recapturing place identification through community heritage marketing. European Journal of Marketing, 50(7/8), pp.1118-1136.

ALKER, Z. and DONALDSON, C., 2018. Digital Heritage. Journal of Victorian Culture, 23(2), pp.220221.

ARTESE, M.T., CIOCCA G. and GAGLIARDI, I., 2017. Evaluating perceptual visual attributes in social and cultural heritage web sites. Journal of Cultural Heritage, 26, pp.91-100.

BEEL, D.E., WALLACE, C.D., WEBSTER, G., NGUYEN, H., TAIT, E., MACLEOD, M. and MELLISH, C., 2017. Cultural resilience: The production of rural community heritage, digital archives and the role of volunteers. Journal of rural studies, 54, pp.459-468.

BLACKBURN, K. 2013. The 'Democratization' of Memories of Singapore's Past. Journal of the Humanities and Social Sciences of Southeast Asia and Oceania/ Bijdragen Tot De Taal-, LandEnVolkenkunde 169 (4): 431-456

CAMERON, F., and KENDERDINE, S.,2010. Theorizing Digital Cultural Heritage. MIT Press, Cambridge.

CASSIDY, L., 2012. Recalling community: Using material culture and digital archives in Salford. Gateways: International Journal of Community Research and Engagement, 5, pp.166-82.

CARLETTI, L., 2016. Participatory heritage: Scaffolding citizen scholarship. International Information \& Library Review, 48(3), pp.196-203.

CRAVEN, J., 2011. Widening access to information: the haves and the have- nots?. Libraries and society: Role, responsibility and future in an age of change, pp.101-118.

DALLAS, C., 2016. Digital curation beyond the "wild frontier": a pragmatic approach. Archival Science, 16(4), pp.421-457. 
DUFFY, P.R.J. and POPPLE, S.E., 2017. Pararchive and Island Stories: collaborative codesign and community digital heritage on the Isle of Bute. Internet Archaeology, (46).

DUMITRESCU, G., LEPADATU, C. and CIUREA, C., 2014. Creating Virtual Exhibitions for Educational and Cultural Development. Informatica economica, 18(1).

DUNFORD, M. and JENKINS, T., 2017. Form and content in digital storytelling. Digital Storytelling" Form and Content. Palgrave MacMillian. pp. 1-17

ECONOMOU, M., 2015. Heritage in the digital age. A companion to heritage studies, 215- 228.

ERSTAD,O. and WERTSCH, J.V. 2008. Tales of mediation: narrative and digital media as cultural tools. Digital Storytelling, Mediatized Stories: Self-Representations in New Media, Peter Lang, New York, NY, pp. 21-40.

GIACCARDI, E. (2012). Heritage and social media: Understanding heritage in a participatory culture, Routledge, Taylor \& Francis Group.

HALBWACHS, M., 1992. On Collective Memory (trans. L. Coser), Chicago: University of Chicago Press.

HARRISON, K., 2018. Ethnography. Oxford University Press.

HENNINGER, M. and SCIFLEET, P., 2016. How are the new documents of social networks shaping our cultural memory. Journal of Documentation, 72(2), pp.277-298.

HOOD, C. and REID, P., 2018. Social media as a vehicle for user engagement with local history: A case study in the North-East of Scotland. Journal of Documentation, 74(4), pp.741-762.

IRACI, J., 2017. The Digitization of VHS Video Tapes - Technical Bulletin 31. Government of Canada. Available at: https://www.canada.ca/en/conservationinstitute/services/conservationpreservationpublications/technical- bulletins/digitizationvhs-video-tapes.html (Accessed 25 April 2019)

ISEKE, J.M., 2011. Indigenous digital storytelling in video: Witnessing with Alma Desjarlais. Equity \& Excellence in Education, 44(3), pp.311-329.

JOHNSON, J.M., 2018. Social Stories: Digital Storytelling and Social Media. In Forum Journal (Vol. 32, No. 1, pp. 39-46). National Trust for Historic Preservation.

KAPSE, A., 2015. Producing film heritage. South Asian Popular Culture, 13(1), pp.89-93.

LABRADOR, A. M. \& CHILTON, E. S. 2009. Re-locating meaning in heritage archives:a call for participatory heritage databases. Computer Applications to Archaelogy. Williamsburgh, Virginia, USA.

MCDONALD, H., 2011. Understanding the antecedents to public interest and engagement with heritage, European Journal of Marketing, Vol. 45 No. 5, pp. 780-804.

MACDONALD, R.L., COULDRY, N. and DICKENS, L., 2015. Digitization and materiality: researching community memory practice today. The Sociological Review, 63(1), pp.102- 120. 
MCLELLAN, H. 2006. Digital storytelling in higher education. Journal of Computing in Higher Education, Vol. 19 No. 1, pp. 65-79.

MAXWELL, A., 2010. Digital archives and history research: feedback from an end-user. Library Review, 59(1), pp.24-39.

MAZZANTI, N., 2011. Challenges of the digital era for film heritage institutions. Digital Agenda for the European Film Heritage. European Commission, DG Information Society and Media.

MILLAR, R.M., 2016. 7 Dialect death? The present state of the dialects of the Scottish fishing communities. In Current Trends in Historical Sociolinguistics (pp. 143-164). Sciendo Migration.

MUTIBWA, D.H., 2016. Memory, storytelling and the digital archive: Revitalizing community and regional identities in the virtual age. International Journal of Media \& Cultural Politics, 12(1), pp.726. 18

NICHOLSON, K., 2017. Innovation in public libraries: Learning from international library practice. Chandos Publishing.

NIEDEREE, C., MEZARIS, V., MAUS, H. and LOGIE, R.H., 2018. Multimedia Preservation: Why Bother?. In Personal Multimedia Preservation (pp. 3-8). Springer, Cham.

NLS, 2015. National Library of Scotland, Project: Digitise. Available at https://www.nls.uk/media/1624630/project-digitise-leaflet.pdf (Accessed 28 April 2019)

ONGENA, G., VAN DE WIJNGAERTW, L.A.L. and HUIZER, E., 2013. Designing online audiovisual heritage services: an empirical study of two comparable online video services. New review of hypermedia and multimedia, 19(1), pp.61-79.

OWENS, T., 2013. Digital Cultural Heritage and the crowd. Curator: The Museum Journal 56(1) (Jan.): 121-130.

PARRY, R. 2010. Museums in a Digital Age. Routledge, Abingdon/New York.

PURKIS, H., 2017. Making digital heritage about people's life stories. International Journal of Heritage Studies, 23(5), pp.434-444.

RIDGE, M., 2013.From Tagging to Theorizing: Deepening Engagement with Cultural Heritage through Crowdsourcing. Curator: The Museum Journal Vol. 56, No. 4.

ROUED-CUNLIFFE, H., and COPELAND, A. (2017). Introduction: What is participatory heritage? Participatory heritage . London, England: Facet.

RUGE, C. \& DENISON, T., 2017. The use of digital image collections and social media amongst Australian historical societies Information Research, 22(4)

RIZVIC, S., DJAPO, N., ALISPAHIC, F., HADZIHALIOVIC , B., CENGIC, F.F., IMAMOVIC, A., OKANOVIC, V. and BOSKOVIC, D., 2017, September. Guidelines for interactive digital storytelling 
presentations of cultural heritage. In 2017 9th International Conference on Virtual Worlds and Games for Serious Applications (VS-Games) (pp. 253-259).

SAGE, M., SINGER, J.B., LA MARRE, A. and RICER, C., 2018. Digital Storytelling. Digital Social Work: Tools for Practice with Individuals, Organizations, and Communities, p.90.

SMIMITE, A., BEGHDADI, A. and CHEN, K., 2013, November. Investigating "the experience effect" in audio quality assessment. In 2013 21st Telecommunications Forum Telfor (TELFOR) (pp. 769772).

STEVENS, M., FLINN, A., SHEPHERD, E., 2010. New frameworks for community engagement in the archive sector: from handing over to handing on. International Journal of Heritage Studies 16 (1e2), pp.59 - 76.

STUEDAHL, D., and MORTBERG, C., 2012. Heritage Knowledge, Social Media and the Sustainability of the Intangible. Heritage and Social Media: Understanding Heritage in a Participatory Culture, pp. 106-125. Routledge, Oxford.

SABHARWAL, A., 2015. Digital curation in the digital humanities: Preserving and promoting archival and special collections. Chandos Publishing

SINN, D., and SYN, S.Y., 2014. Personal documentation on a social network site: Facebook, a collection of moments from your life? Archival Science, Vol 14 No 2, pp. 95- 124. 19

TAIT, E., MACLEOD, M., BEEL, D., WALLACE, C., MELLISH, C. and TAYLOR, S., 2013. Linking to the past: an analysis of community digital heritage initiatives. Aslib Proceedings , 65 (6), pp. 564580.

TASKER, G. and LIEW, C.L., 2018. 'Sharing my stories': genealogists and participatory heritage. Information, Communication \& Society, pp.1-18.

TAYLOR, J. and GIBSON, L.K., 2017. Digitisation, digital interaction and social media: embedded barriers to democratic heritage. International Journal of Heritage Studies, 23(5), pp.408-420.

VAN MAANEN, J., 2011. Tales of the field: On writing ethnography. Chicago: University of Chicago Press.

VAN VLIET, H. and HEKMAN, E., 2012. Enhancing user involvement with digital cultural heritage: The usage of social tagging and storytelling. First Monday, 17(5). 